2nd Department of Medicine and Cardiology Center, Medical Faculty, Albert Szent-Györgyi Clinical Center, University of Szeged

\title{
Left ventricular rotational and strain analysis by three-dimensional speckle tracking echocardiography in cardiomyopathies
}

\section{Anita Kalapos MD}

PhD Thesis

Tutor:

Prof. Attila Nemes MD, PhD, DSc

Szeged

2016 


\section{Full papers}

I. Nemes A, Kalapos A, Domsik P, Lengyel C, Orosz A, Forster T. Correlations between echocardiographic aortic elastic properties and left ventricular rotation and twist Insights from the three-dimensional speckle-tracking echocardiographic MAGYARHealthy Study. Clin Physiol Funct Imaging 2013; 33: 381-385. (Impact factor: 1.376)

II. Nemes A, Kalapos A, Domsik P, Forster T. Identification of Left Ventricular "Rigid Body Rotation" by Three-Dimensional Speckle-Tracking Echocardiography in a Patient with Noncompaction of the Left Ventricle: A Case from the MAGYAR-Path Study. Echocardiography 2012; 29: E237-E240. (Impact factor: 1.239)

III. Kalapos A, Domsik P, Forster T, Nemes A. Left Ventricular Strain Reduction Is Not Confined to the Noncompacted Segments in Noncompaction CardiomyopathyInsights from the Three-Dimensional Speckle Tracking Echocardiographic MAGYAR-Path Study. Echocardiography 2014; 31: 638-643. (Impact factor: 1.254)

IV. Kalapos A, Domsik P, Forster T, Nemes A. Comparative evaluation of left ventricular function by two-dimensional echocardiography and three-dimensional speckletracking echocardiography in noncompaction cardiomyopathy Results from the MAGYAR-Path Study. Orv Hetil 2013; 154: 1352-1359.

V. Nemes A, Domsik P, Kalapos A, Gavallér H, Forster T, Sepp R. Quantification of Changes in Septal Strain after Alcohol Septal Ablation in Hypertrophic Obstructive Cardiomyopathy-Cases from the Three-Dimensional Speckle Tracking Echocardiographic MAGYAR-Path Study. Echocardiography 2013; 30: E289-E291. (Impact factor: 1.254) 


\section{Abstracts}

I. Nemes A, Kalapos A, Domsik P, Forster T. Left ventricular strain reduction is not confinied to the noncompacted segments in noncompaction cardiomyopathy - a threedimensional speckle tracking echocardiographic study. Eur Heart J Cardiovasc Imaging 2013; 14 (Suppl 2.); ii35.

II. Nemes A, Kalapos A, Domsik P, Lengyel Cs, Orosz A, Forster T. Relationship between three-dimensional speckle tracking echocardiography-derived left ventricular rotation and twist and aortic stiffness. Eur Heart J 2012; 33 (Suppl.1.): 851 
Table of contents

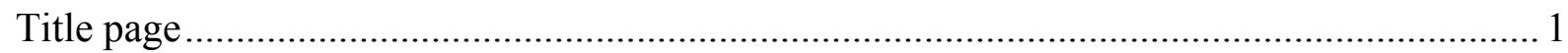

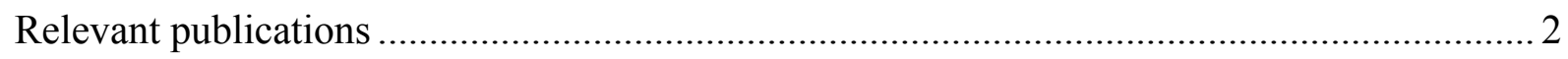

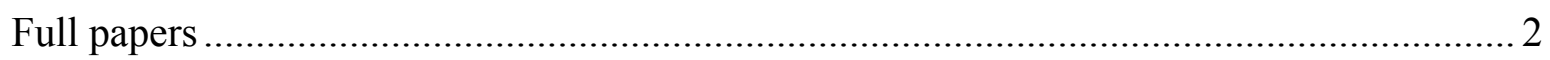

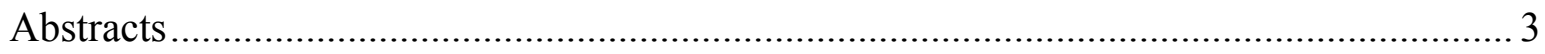

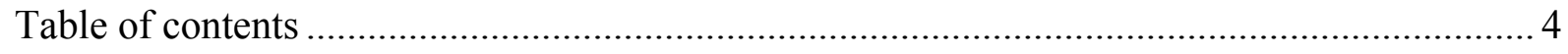

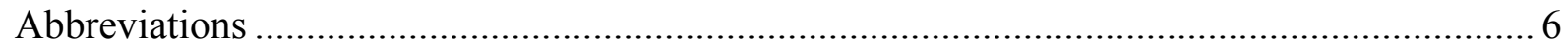

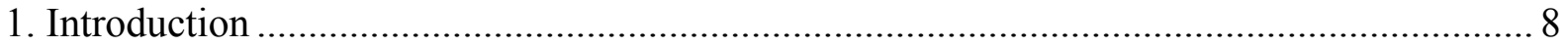

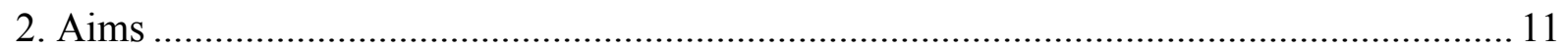

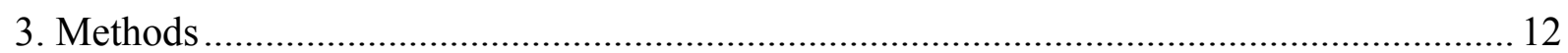

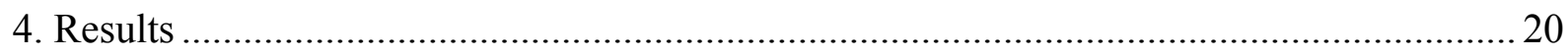

4.1. Correlations between echocardiographic aortic elastic properties and left ventricular

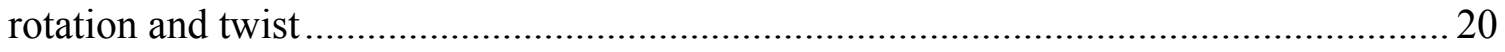

4.2. Identification of left ventricular 'rigid body rotation' by three-dimensional speckletracking echocardiography in a patient with noncompaction of the left ventricle.

4.3. Left ventricular strain reduction is not confined to the noncompacted segments in noncompaction cardiomyopathy

4.4. Comparative evaluation of left ventricular function by two-dimensional echocardiography and three-dimensional speckle-tracking echocardiography in noncompaction cardiomyopathy

4.5. Quantification of changes in septal strain after alcohol septal ablation in

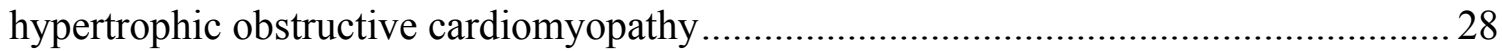

5. Discussion

5.1. Correlations between echocardiographic aortic elastic properties and left ventricular rotation and twist

5.2. Identification of left ventricular 'rigid body rotation' by three-dimensional speckletracking echocardiography in a patient with noncompaction of the left ventricle.

5.3. Left ventricular strain reduction is not confined to the noncompacted segments in noncompaction cardiomyopathy

5.4. Comparative evaluation of left ventricular function by two-dimensional echocardiography and three-dimensional speckle-tracking echocardiography in noncompaction cardiomyopathy 
5.5. Quantification of changes in septal strain after alcohol septal ablation in

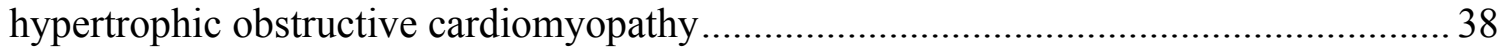

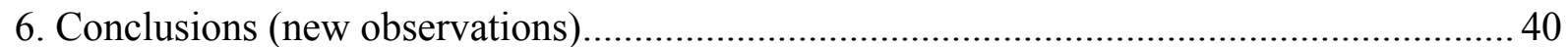

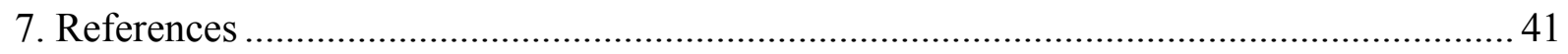

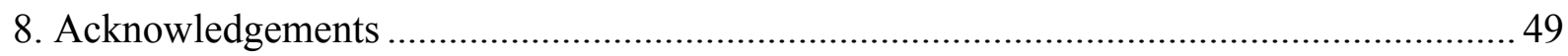

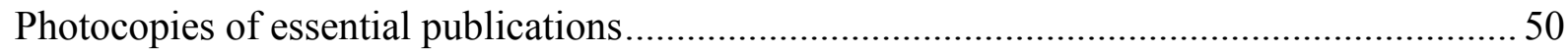




\section{Abbreviations}

2D: $\quad$ two-dimensional

2DSTE: two-dimensional speckle-tracking echocardiography

3D: three-dimensional

3DS: $\quad$ three-dimensional strain

3DSTE: three-dimensional speckle-tracking echocardiography

AP2CH: apical 2-chamber view

AP4CH: apical 4-chamber view

ACE: angiotensin-converting enzyme

Ao: $\quad$ ascending aorta

AS: $\quad$ area strain

CK: $\quad$ creatine kinase

CS: $\quad$ circumferential strain

DBP: $\quad$ diastolic blood pressure

DD: diastolic diameter of the ascending aorta

DS: $\quad$ systolic diameter of the ascending aorta

EDV: $\quad$ end-diastolic volume

EF: $\quad$ ejection fraction

ESV: end-systolic volume

HCM: hypertrophic cardiomyopathy

LA: $\quad$ left atrium

LS: $\quad$ longitudinal strain

LV: $\quad$ left ventricular

LVOT: left ventricular outflow tract

'MAGYAR': 'Motion Analysis of the heart and Great vessels bY three-dimensionAl speckle-tRacking echocardiography'

MEDT: $\quad$ maximal end-diastolic thickness

NCCM: noncompaction cardiomyopathy

PTSMA: percutaneous transluminal septal myocardial ablation

RA: $\quad$ right atrium

RS: $\quad$ radial strain

$\mathrm{RV}: \quad$ right ventricle

RT3DE: $\quad$ real-time three-dimensional echocardiography 
SBP: $\quad$ systolic blood pressure

SD: $\quad$ standard deviation

STE: $\quad$ speckle-tracking echocardiography

WMS: $\quad$ wall motion score 


\section{Introduction}

Measurement of left ventricular (LV) function and regional wall motion analysis of the LV is one focus of cardiac ultrasound technology. For decades, two-dimensional (2D) and Doppler echocardiography have played an essential role in evaluating left ventricular (LV) function. Measurements of LV ejection fraction (EF) as well as the visual analysis of myocardial wall motion have significant interobserver variability in the evaluation of global and regional LV performance. Just over a decade ago, speckle-tracking echocardiography (STE), a method based on tracking of speckle patterns created by interference of the ultrasound beams in the myocardium became available and was proposed $(1,2)$, then validated (3-5) as an alternative tool for measuring myocardial function. STE enables more accurate measurements of LV dimensions and strain parameters and has potential to be used in the clinical practice for quantifying myocardial strain (3). Measurement of regional deformation of the myocardium has been applied as an objective methodology for the assessment of regional myocardial function. Regional strain and strain-rate estimation with tissue Doppler imaging based on tissue velocity was first applied to assess regional wall deformation (5-8). However, strain and strain rate can be accurately estimated only at regions parallel to the ultrasound beam due to angle dependence of the Doppler method (9). STE is based on a B-mode image, so it is angle independent of the ultrasound beam. STE has been used to assess LV function and regional wall motion abnormalities (10), diastolic function (11), and cardiac dyssynchrony to predict response for cardiac resynchronization therapy (12, 13). However, currently available STE methodology has limitations due to its 2D imagingbased method. Wall deformations are three-dimensional (3D), which affects tracking accuracy. Therefore, more accurate calculation of LV strain requires an advanced technology that uses a $3 \mathrm{D}$ tracking system.

Three-dimensional (3D) echocardiography has been applied to assess LV volume and mass (14-18) and LV global and regional wall motion, which is based on time-volume analysis of global and segmental LV volumes (19). Three-dimensional speckle-tracking echocardiography (3DSTE) is a novel non-invasive imaging modality. 3D databases are collected digitally from the heart or a region of the heart with ECG gating using a special echocardiography device and so called matrix transducers. The resulting 'echo mist' can be processed with special online or offline softwares later. 3DSTE creates a spatial model of the heart chambers with 3D tracing of certain pixels (speckles), enabling quantitative analysis of 
changes in volumes during cardiac cycles as well as evaluation of global and regional wall motions. The method was introduced in Hungary in 2012 (20).

In the normal heart, the $\mathbf{L V}$ base rotates clockwise while the apex rotates counterclockwise during systole, producing a 'towel-wringing' motion of the heart. The net difference between the LV base and LV apex is called 'net twist angle' (21). The LV twist represents a phenomenon that links systolic contraction with diastolic relaxation (22). However, little is known about the factors affecting LV rotational mechanics, even in healthy subjects.

There is an interaction between the LV, as a pump, and the vascular system, as a load, which plays a crucial role in determining cardiac output (23). The normal human aorta is not a stiff tube, but is characterized by elastic properties (24). Aortic stiffness describes the elastic resistance the aorta sets against its distension, while the inverse of stiffness is compliance (distensibility), which describes the ease of systolic aortic expansion (24, 25). Echocardiography can be used for non-invasive evaluation of both aortic elastic properties and rotational mechanics. Recently, 3DSTE was found to be feasible for the assessment of LV rotational parameters $(22,26)$.

Noncompaction cardiomyopathy (NCCM) is a rare congenital heart disease. It develops as a consequence of absent or incomplete myocardial compaction during embryonic morphogenesis $(27,28)$. Echocardiography is the standard diagnostic tool for NCCM, and Jenni et al. (28) proposed diagnostic criteria based on end-systolic ratio of noncompacted to compacted layers above 2 with evidence of direct blood flow from the ventricular cavity into deep intertrabecular recesses by color Doppler. Cardiac MRI is useful to confirm or rule out NCCM when the apex is difficult to visualize. Normally, compaction progresses from the epicardium to the endocardium, and from the base toward the apex of the heart, therefore, this disease mainly affects the endocardium and the apex of the heart (29). Prognostic significance of NCCM is that it is often accompanied by the early development of systolic or diastolic ventricular dysfunction, which may lead to even heart failure, and the incidence of malignant arrhythmia is also increased in this patient population. Hypertrabecularization of the myocardium significantly increases the incidence of systemic embolization as well (30). Hungarian literature regarding the disease is limited $(29,31,32)$. Van Dalen et al. were the first using 2DSTE to demonstrate that the direction of LV basal rotation and that of LV apical rotation are the same, resulting in the near absence of LV twist in NCCM patients, which they called as 'LV solid/rigid body rotation' (33). 
In a recent volumetric real-time three-dimensional echocardiographic (RT3DE) study, both noncompacted and compacted LV segments were found to have comparably reduced regional LV systolic function (34). These results suggest that systolic LV dysfunction observed in NCCM is not confined to noncompacted LV segments (34).

Hypertrophic cardiomyopathy $(\mathrm{HCM})$ is a complex, relatively common genetic cardiac disease, which is heterogeneous with respect to gene mutations, clinical symptoms, prognosis, and treatment strategies (35). HCM represents a generalized myopathic process affecting both ventricular and atrial myocardium (36). Most of the patients are in steady condition, although HCM is known as one of the most common cause of sudden death in juvenile patients (35). HCM is characterized by excessive asymmetric LV hypertrophy involving primarily the interventricular septum (35). It is known, that diastolic LV dysfunction is more common in HCM than systolic dysfunction. Currently, only a few studies are available regarding the usefulness of 3DSTE in $\operatorname{HCM}(22,37)$. 


\section{Aims}

To evaluate correlations between echocardiographic aortic elastic properties and LV rotational mechanics in healthy subjects.

To demonstrate the usefulness of 3DSTE in the assessment of the near absence of LV twist, called as 'LV solid/rigid body rotation' in a NCCM patient.

To evaluate different contributions of noncompacted and compacted LV segments to global LV dysfunction by 3DSTE-derived strain parameters in NCCM.

To compare global and regional LV volumes and function by $2 \mathrm{D}$ echocardiography and 3DSTE in NCCM and to assess LV rotational mechanics in a series of NCCM patients by 3DSTE.

To demonstrate the possible clinical utility of 3DSTE in the evaluation of septal strain changes in obstructive HCM patients after percutaneous transluminal septal myocardial ablation (PTSMA). 


\section{Methods}

Patient population (general considerations). All healthy subjects and patients have been included in the MAGYAR-Healthy Study and MAGYAR-Path Study (Motion Analysis of the heart and Great vessels bY three-dimensionAl speckle-tRacking echocardiography in Healthy subjects and in Pathological cases). These studies have been organized at the 2nd Department of Medicine and Cardiology Center, University of Szeged, Hungary to evaluate usefulness, diagnostic and prognostic values of 3DSTE-derived volumetric, strain, rotational etc. parameters in healthy volunteers as well as in pathological cases ('Magyar' means 'Hungarian' in Hungarian language).

NCCM and HCM were defined regarding current guidelines $(28,38)$. The following echocardiographic criteria were used for NCCM (Figure 1a, 1b):

(1) Excessively thickened LV myocardial wall with 2-layered structure comprising of a compacted layer on the epicardial side and a noncompacted layer with prominent trabeculations and deep intertrabecular recesses on the endocardial side.

(2) Noncompacted/compacted myocardium thickness ratio is $>2$ measured at the moment of maximal thickness in end-systole.

(3) Color Doppler evidence of deep intertrabecular recesses communicating with the LV cavity.

(4) Absence of coexisting cardiac anomalies.
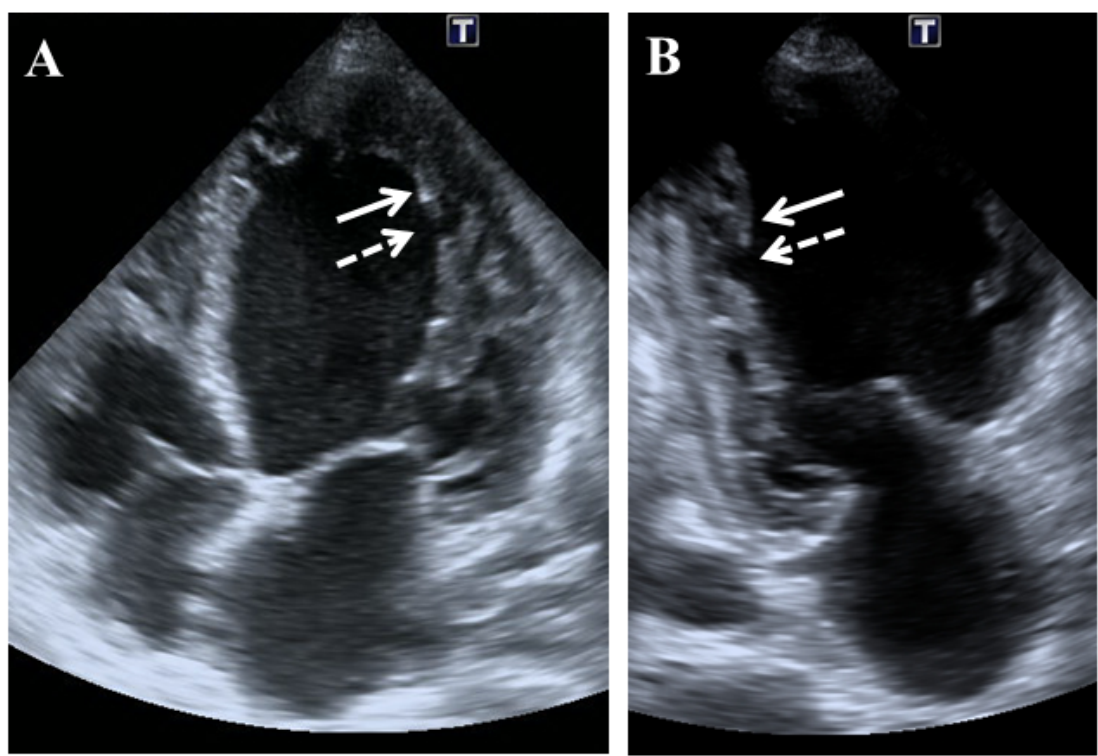

Figure 1a. Typical two-dimensional echocardiographic apical four-chamber (A) and two-chamber (B) views demonstrating prominent trabeculations (white arrows) and intertrabecular recesses (dashed arrows) in a patient with typical features of noncompaction cardiomyopathy. 

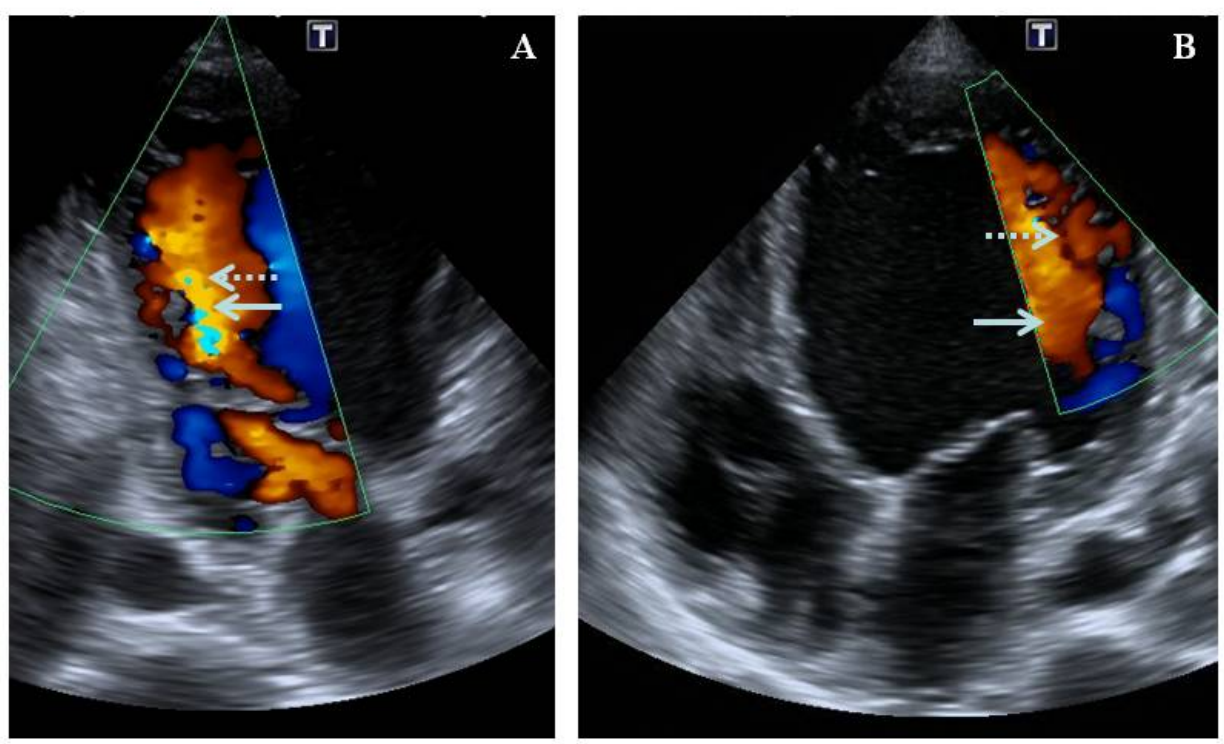

Figure 1b. Typical two-dimensional echocardiographic apical two-chamber (A) and four-chamber (B) views demonstrating prominent trabeculations (white arrows) and intertrabecular recesses (dashed arrows) with Color Doppler echocardiography demonstrating communication with the left ventricular cavity in a patient with noncompaction cardiomyopathy.

In case of all patients, complete 2D Doppler echocardiography study was performed with 3DSTE measurements. Healthy volunteers had no disease or condition that may influence the results. Informed consent was obtained from each participant, and the study protocol compiles with the Declaration of Helsinki (1975) and has been approved by the Institutional Review Board.

Transthoracic echocardiography. All subjects underwent a complete 2D transthoracic Doppler echocardiographic study using a Toshiba Artida ${ }^{\mathrm{TM}}$ echocardiography equipment (Toshiba, Tokyo, Japan) with a PST-30SBP (1-5 MHz) phased-array transducer in left lateral decubitus position from multiple windows. All echocardiographic studies were digitally stored and evaluated, the examiner was blinded to the clinical data. All echocardiographic measurements were averaged from 3 heartbeats. M-mode echocardiography was used to measure LV internal dimensions. LV diameters, volumes and EF were measured using the Teichholz's formula. In case of NCCM, the systolic performance of compacted and noncompacted LV segments was assessed using the wall motion score (WMS): $1=$ normokinesis,

2 = hypokinesis, 3 = akinesis, $4=$ dyskinesis. WMS index was calculated as a ratio of WMS and the number of analyzed segments. During evaluations, 16-segment model was used. 
Measurement of blood pressure values. Systolic and diastolic blood pressure values (SBP and DBP, respectively) were measured in supine position with a mercury cuff sphygmomanometer on the right arm after 10 minutes of rest. The first and the fifth Korotkoff sounds were taken for the SBP and DBP. Coffee, tea, other types of beverages, or cigarettes were not used or ingested from half an hour to an hour before the blood pressure measurements. The average of three consecutive measurements was accepted.

Evaluation of aortic stiffness parameters. Aortic elastic properties were calculated according to the literature $(25,39)$. Systolic and diastolic ascending aortic diameters (DS and $\mathrm{DD}$, respectively) were recorded in M-mode at a level of $3 \mathrm{~cm}$ above the aortic valve from parasternal long-axis view (Figure 2).

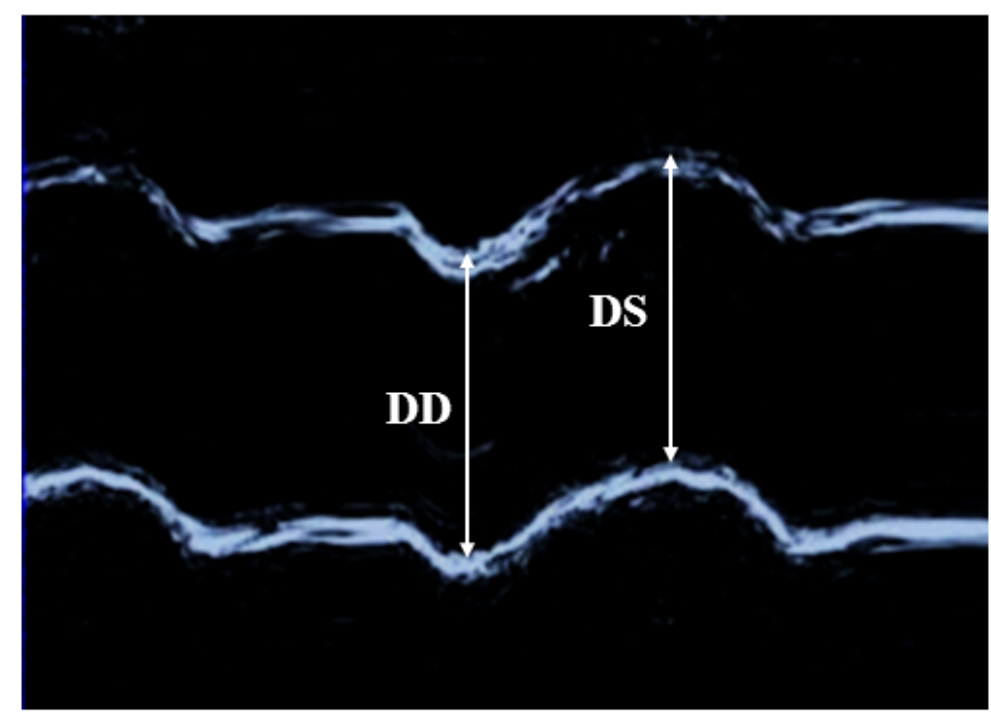

Figure 2. Measurement of systolic (DS) and diastolic (DD) diameters of the ascending aorta are shown with M-mode tracing obtained at a level $3 \mathrm{~cm}$ above the aortic valve from parasternal long-axis view.

DS and DD were measured at the time out of maximum aortic anterior motion and at the peak of the QRS complex, respectively. All measurements were repeated 3 times, and average data were given. The following aortic elastic properties were calculated:

- Aortic strain $=(\mathrm{DS}-\mathrm{DD}) / \mathrm{DD}$

- Aortic stiffness index $(\beta)=\ln (\mathrm{SBP} / \mathrm{DBP}) /[(\mathrm{DS}-\mathrm{DD}) / \mathrm{DD}]$, where 'ln' is the natural logarithm.

- Aortic distensibility $=2 \times(\mathrm{DS}-\mathrm{DD}) /[(\mathrm{SBP}-\mathrm{DBP}) \mathrm{x} \mathrm{DD}]$. 
Three-dimensional speckle-tracking echocardiography. 3DSTE studies were performed with the same Toshiba Artida ${ }^{\mathrm{TM}}$ echocardiography equipment (Toshiba, Tokyo, Japan) with a 1-4 MHz matrix phased-array PST-25SX transducer. Within a single breath-hold and during a constant RR interval, 6 wedge-shaped subvolumes were acquired from an apical window to create full-volume 3D data sets. Chamber quantification was performed using 3D Wall Motion Tracking software version 2.7 (Toshiba Medical Systems). The apical two- (AP2CH) and four-chamber $(\mathrm{AP} 4 \mathrm{CH})$ views and 3 short-axis views at different LV levels from the base to the apex were automatically selected from the real-time 3D echocardiographic pyramidal dataset at end-diastole by the software. Two points of the endocardium at the edges of the mitral valve and one at the apex were marked manually on the $\mathrm{AP} 2 \mathrm{CH}$ and $\mathrm{AP} 4 \mathrm{CH}$ views. Subsequently, the endocardial surface was manually adjusted in all apical and short-axis views. Then, the $3 \mathrm{D}$ endocardial surface was automatically reconstructed and tracked in $3 \mathrm{D}$ space throughout the cardiac cycle. The device calculated the end-diastolic volume (EDV) and the end-systolic volume (ESV), ejection fraction (EF) and left ventricular mass. Curves were generated by the software for quantification of the 3DSTE peak values of global and regional (apical, midventricular and basal) LV rotation and twist (Figures 3,4) as well as for quantification of 3DSTE-derived regional radial (RS), longitudinal (LS), circumferential (CS), 3D strain (3DS) and area tracking/strain (AS) values using a 16-segment LV model (Figures 5,6). All rotational and twist values were averaged from three measurements. See Table 1 for the list of definitions of different strain parameters. 

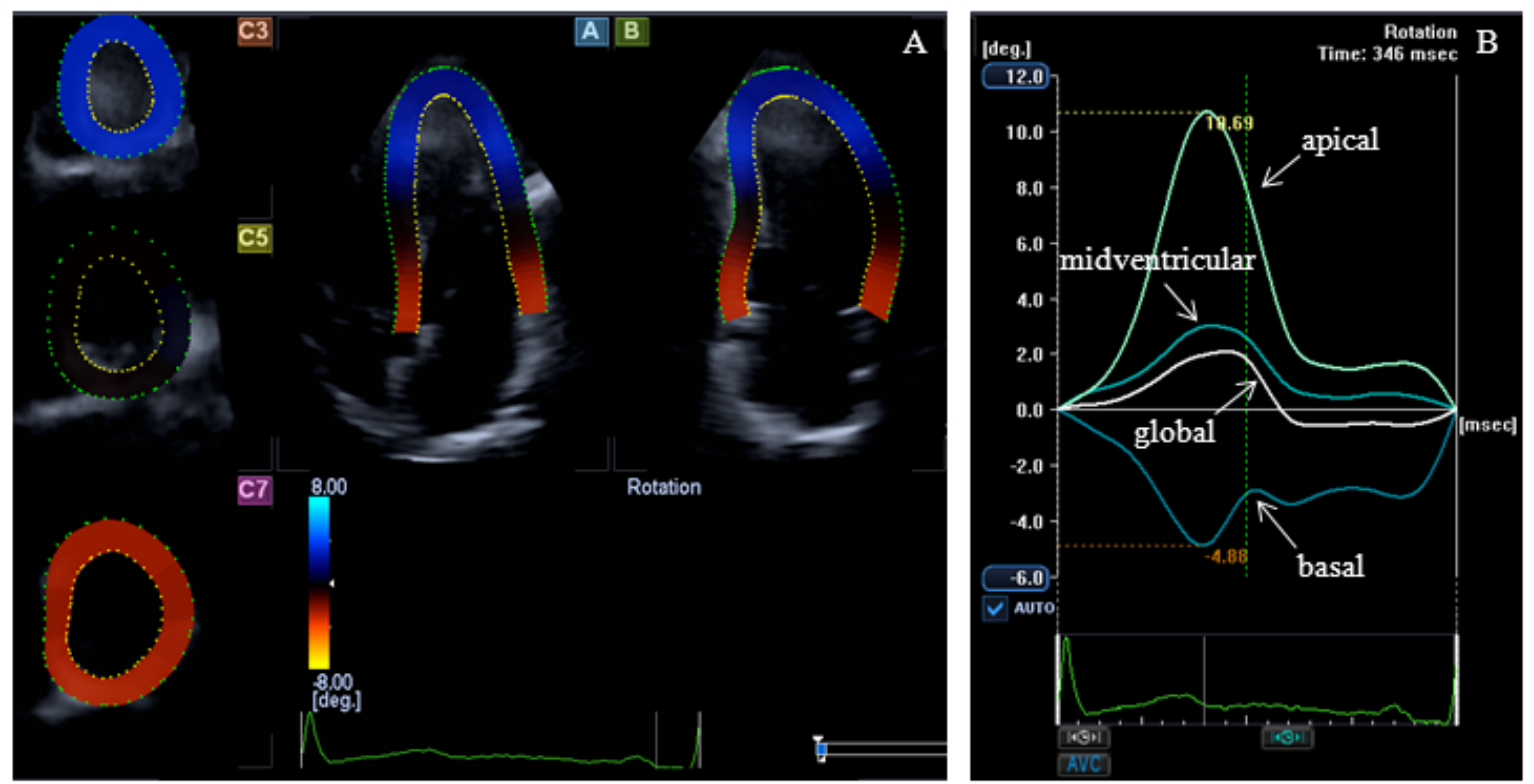

Figure 3. Apical two- and four-chamber views and 3 short axis views at different left ventricular levels are presented in a healthy woman (A). Global, apical, midventricular and basal regional left ventricular rotation curves detected by three-dimensional speckle-tracking echocardiography are demonstrated in a normal case. The adequate rotational directions are counterclockwise motion of the left ventricular apex expressed with positive values and clockwise rotation of the left ventricular base with negative values (B). 


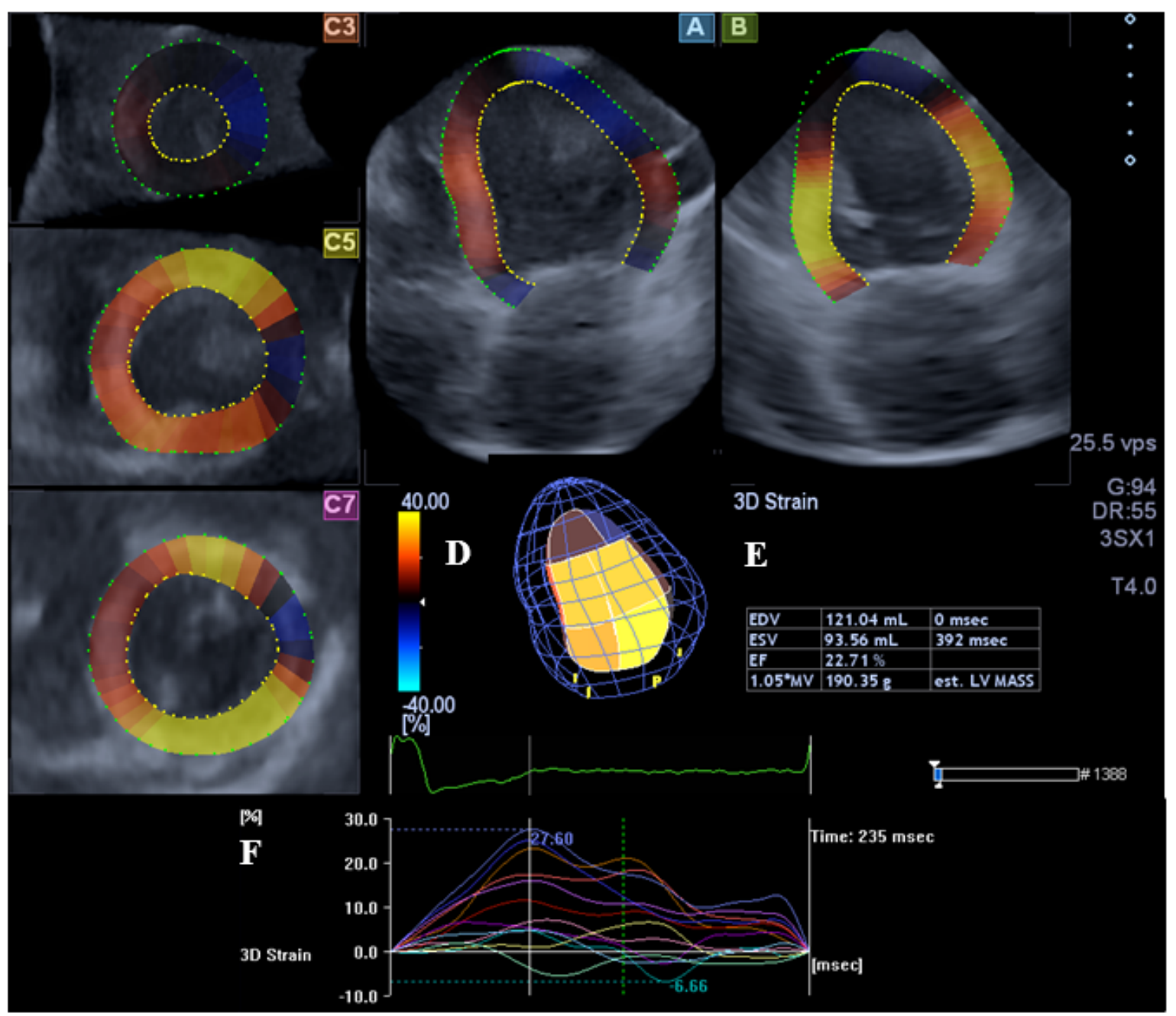

Figure 4. Apical four-chamber (A) and two-chamber views (B) and 3 short axis views (C3, C5, C7) at different levels of the left ventricle (LV) extracted from the threedimensional (3D) echocardiographic dataset are presented. A 3D cast of the LV (D) and calculated volumetric and functional LV parameters (EDV: end-diastolic volume, ESV: end-systolic volume, EF: ejection fraction, estimated LV mass) are also demonstrated (E) together with segmental 3D strain curves in a patient with noncompaction cardiomyopathy. 

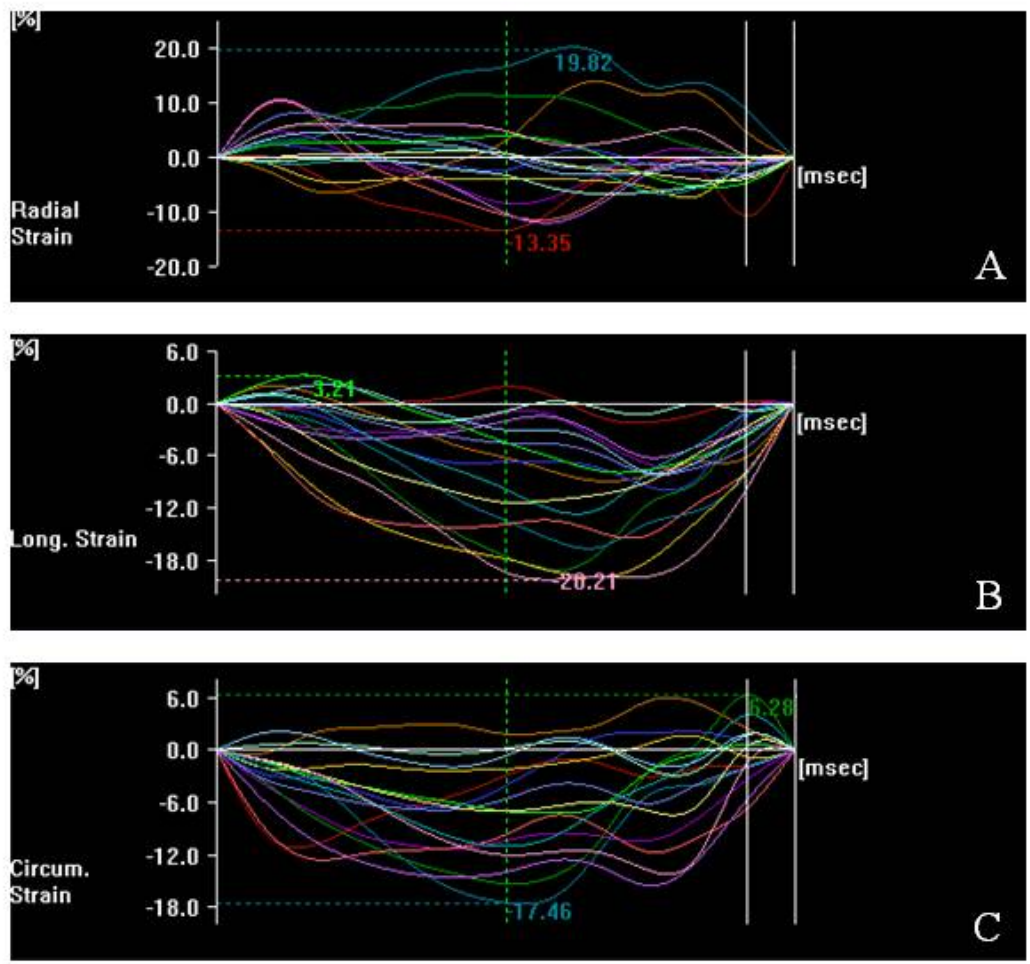

Figure 5. Radial (A), circumferential (B) and longitudinal (C) time-strain curves of the left ventricular segments in a patient with noncompaction cardiomyopathy. The provided parameters are percentage values characterizing changes in the lengths of left ventricular segments throughout the cardiac cycle.
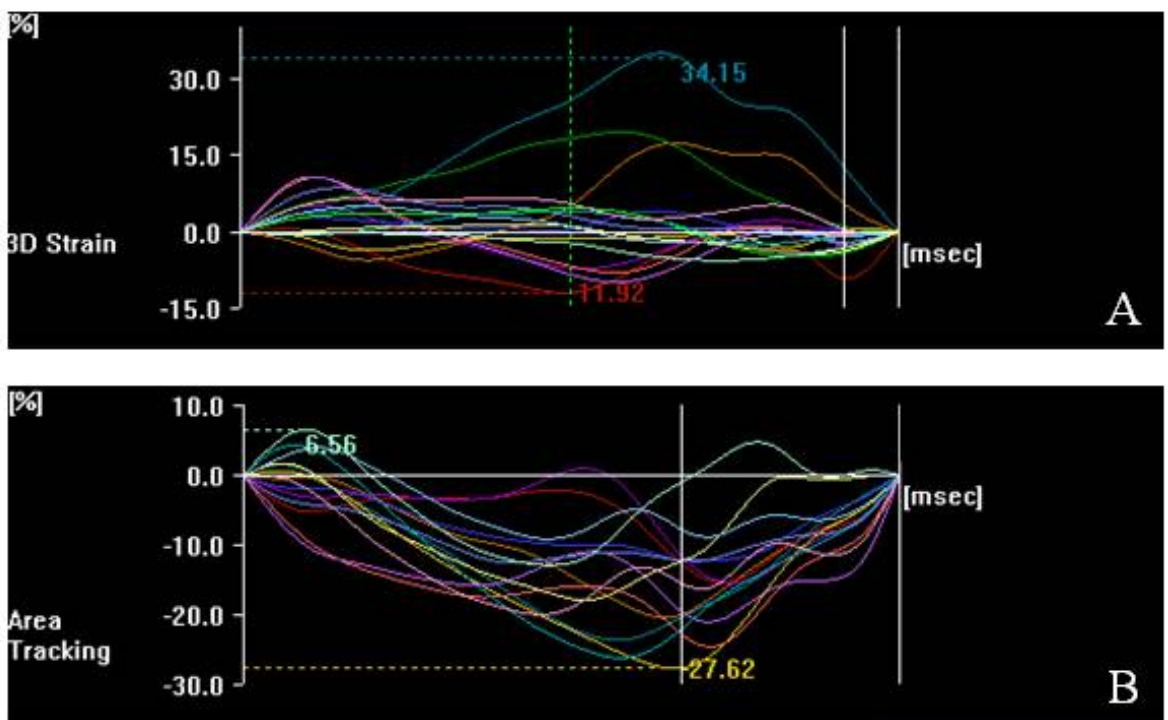

Figure 6. Segmental 3D (A) and area (B) time-strain curves of the left ventricle in a patient with noncompaction cardiomyopathy. The provided parameters are percentage values characterizing changes in the lengths of left ventricular segments throughout the cardiac cycle. 
Table 1. List of definitions of different strain parameters

Radial strain $\quad$ Strain (\%) perpendicular to the endocardial contour. It is measured by measuring the radial change in the length between the endocardium and the epicardium in short-axis views.

Longitudinal strain Strain (\%) parallel to the endocardial contour (usually negative values for the LV). It is measured in apical longaxis views to capture the longitudinal movement.

Circumferential strain $\quad$ Strain (\%) circumferential to the endocardial contour. It is measured in short-axis views by measuring the change in length along the circumference of the myocardium.

3D strain Strain (\%) in wall thickening. 3DS combines the measurements of all three strain parameters (longitudinal, circumferential, and radial) as it tracks speckles in 3D, with direction and magnitude similar to radial strain.

\begin{tabular}{ll}
\hline Area strain & $\begin{array}{l}\text { Area strain tracks an entire square-shaped area, and } \\
\text { endocardial area change ratio }(\%) \\
\text { change in area. }\end{array}$
\end{tabular}

Abbreviations: LV: left ventricle, 3D: three-dimensional, 3DS: three-dimensional strain.

Statistical analysis. Continuous data are expressed as mean \pm SD. Categorical data are given as absolute numbers or percentages where appropriate. Independent samples Student's t-test was used to compare continuous variables and chi-square test and Fisher's exact test were used to compare categorical ones. Numerical correlations were established by Pearson's correlation. For all tests, $\mathrm{p}<0.05$ was considered to be statistically significant. MedCalc software was used for statistical calculations (MedCalc, Mariakerke, Belgium). 


\section{Results}

4.1. Correlations between echocardiographic aortic elastic properties and left ventricular rotation and twist

Patient population. The current study comprised of 26 healthy subjects (mean age: $34.5 \pm 9.8$ years, 13 males). In all cases, complete Doppler transthoracic echocardiography was performed with the evaluation of aortic elastic properties and 3DSTE. None of the subjects had any known disease which could have affected our results.

2D echocardiography. Transthoracic 2D echocardiographic data and aortic elastic properties of the healthy subjects are presented in Table 2. None of the subjects had significant (> grade 1) valvular insufficiency or stenosis.

Table 2. Echocardiographic data and elastic properties of the subjects

Parameter Value

LV diastolic diameter $(\mathrm{mm})$ $46.2 \pm 4.9$

LV systolic diameter (mm) $29.6 \pm 4.6$

LV diastolic volume (ml)

$100.1 \pm 25.1$

LV systolic volume (ml)

$34.1 \pm 13.2$

Interventricular septum (mm)

$10.2 \pm 2.3$

LV posterior wall $(\mathrm{mm})$

$10.6 \pm 2.1$

LV ejection fraction (\%)

$65.8 \pm 8.2$

DS (mm)

$33.1 \pm 3.9$

$\mathrm{DD}(\mathrm{mm})$

$28.9 \pm 3.3$

DS-DD (mm)

$4.13 \pm 2.33$

Aortic strain

$0.131 \pm 0.094$

Aortic distensibility $\left(\mathrm{cm}^{2} /\right.$ dynes $\left.10^{-6}\right)$

$3.61 \pm 2.54$

Aortic stiffness index

$4.08 \pm 0.79$

Abbreviations: LV: left ventricular, DS: systolic diameter of the ascending aorta, DD: diastolic diameter of the ascending aorta 
3DSTE. During 3DSTE, basal LV rotation proved to be $-2.42 \pm 1.43$ degree, while apical LV rotation was $8.56 \pm 1.43$ degree, therefore LV twist was $11.01 \pm 5.19$ degree.

Correlations between LV rotational parameters and aortic elastic properties. Apical LV rotation correlated with aortic distensibility $(r=-0.36, p<0.05)$ and aortic stiffness index $(\mathrm{r}=0.41, \mathrm{p}<0.05)$. LV twist showed similar correlation with aortic stiffness index $(r=0.42$, $\mathrm{p}<0.05)$. No correlation was demonstrated between other 2D echocardiographic data and echocardiographic aortic elastic properties.

\subsection{Identification of left ventricular 'rigid body rotation' by three-dimensional speckle- tracking echocardiography in a patient with noncompaction of the left ventricle}

We present a 58 year-old woman, who was referred to our Catheterization Laboratory due to 3 months' history of effort dyspnea and chest pain. Chronic obstructive pulmonary disease, left bundle branch block, mitral regurgitation, hyperlipidaemia, spondylosis and osteoporosis were in her past medical history. Seven years ago, coronary angiography was performed due to chest pain with negative result. Recently, repeated cardiac catheterization found normal epicardial coronary arteries again. For demonstrative purposes, 3D echocardiographic images of a 51 year-old woman without known cardiovascular diseases are also presented.

During 2D transthoracic echocardiographic evaluation, diffuse myocardial lesion and severely reduced LV function with EF of $22 \%$ were found. Color Doppler echocardiography identified hypertrabecularization of the LV apex, anterior, lateral and posterior walls with deep intertrabecular recesses confirming the diagnosis of NCCM in accordance with the guidelines (Figure 7). 

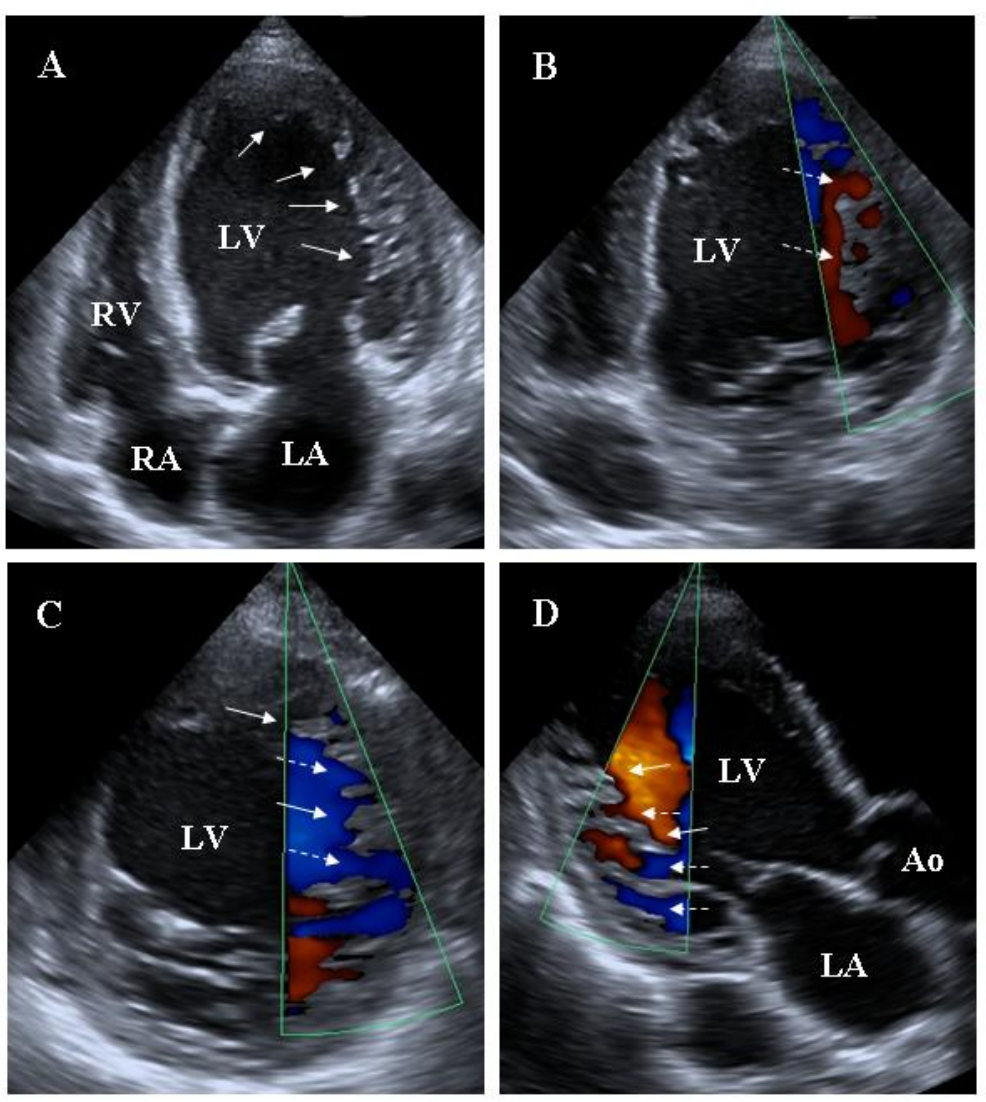

Figure 7. Identification of left ventricular wall hypertrabecularizations (see arrows) and intertrabecular recesses (see dashed arrows) by two-dimensional echocardiography (A) with color Doppler imaging (B-D) in apical 4-chamber (A, B), cross-sectional (C) and apical 3-chamber views (D) suggesting noncompaction of the left ventricle in the present case.

Abbreviations: Ao: ascending aorta, LV: left ventricle, LA: left atrium, RV: right ventricle, RA: right atrium.

For a better evaluation of NCCM, 3DSTE was performed using a 1-4 MHz matrix phased-array transducer. The AP2CH, AP4CH, and 3 short axis views at different LV levels from the base to the apex were automatically selected from the real-time 3D echocardiographic pyramidal dataset at end-diastole by the software (Figures 8A and 9A). Two points of the endocardium at the edges of the mitral valve and one at the apex were marked manually on the apical four- and the orthogonal two-chamber views. Subsequently, the endocardial surface was manually adjusted in all the apical and short-axis views. Then, the 3D endocardial surface was automatically reconstructed and tracked in 3D space throughout the cardiac cycle. Curves were generated by the software for quantification of the 3DSTE peak values of global and regional (apical, midventricular and basal) LV rotation and twist (Figures 8B and 9B). Results of the present NCCM case suggested movement of all regions in almost the same clockwise direction. 

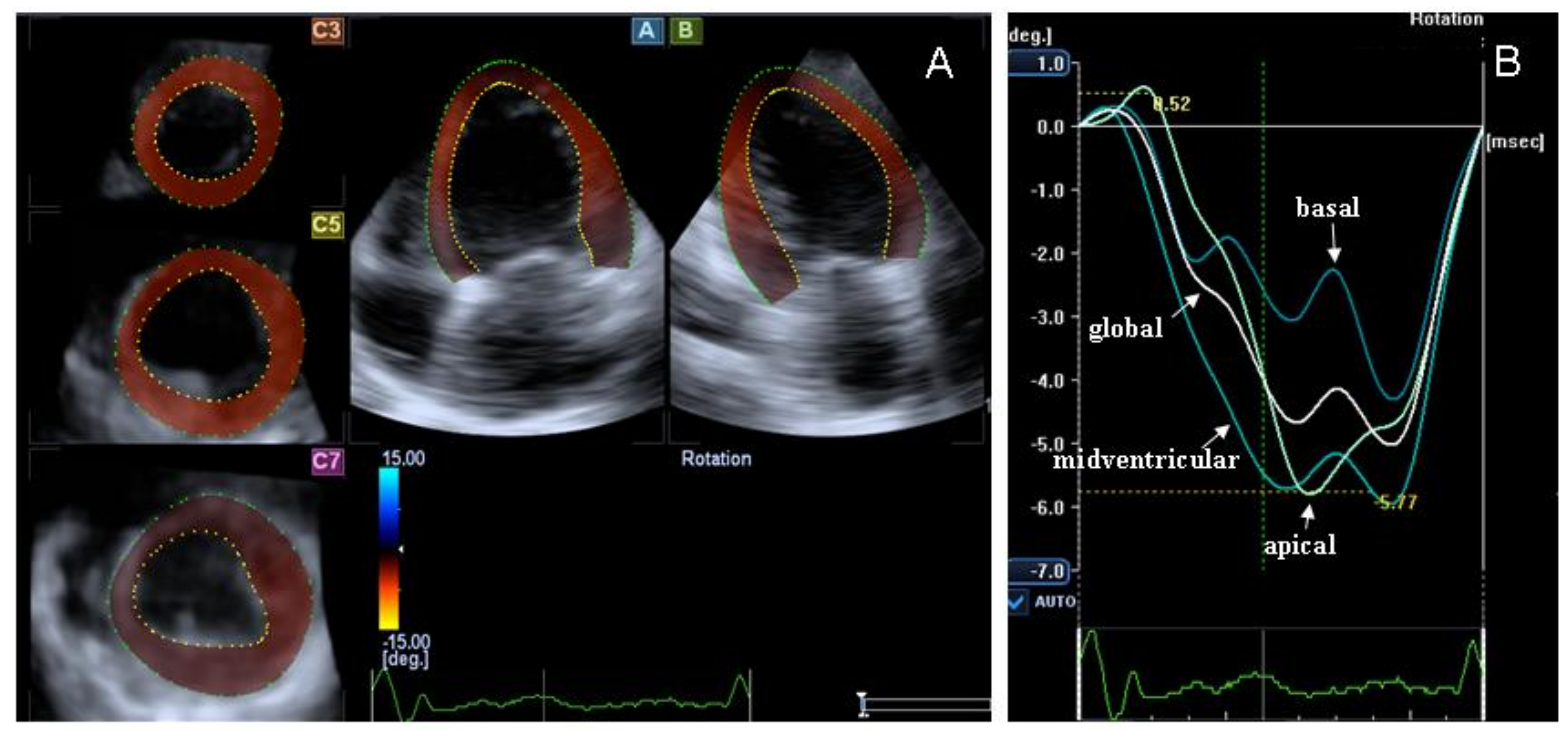

Figure 8. The apical two- and four-chamber views and 3 short axis views at different left ventricular levels from the base to the apex were automatically selected from the realtime 3-dimensional echocardiographic pyramidal dataset by the software (A). Curves for quantification of global and regional (apical, midventricular and basal) left ventricular rotation detected by three-dimensional speckle-tracking echocardiography in a patient with noncompaction of left ventricle. All peak values of left ventricular rotation were negative demonstrating clockwise movement of all regions in this case suggesting left ventricular 'rigid body rotation' (B).
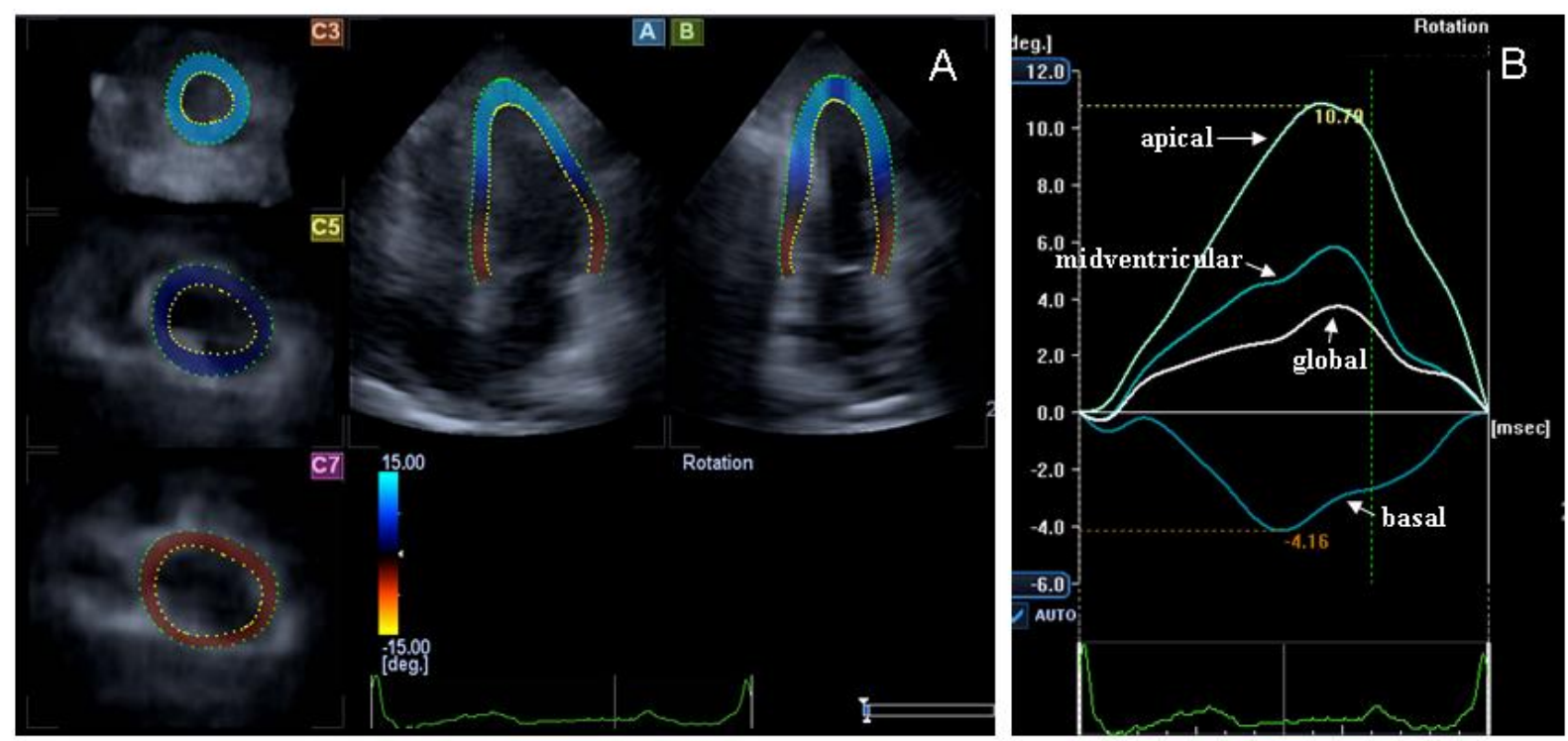

Figure 9. The apical two- and four-chamber views and 3 short axis views at different left ventricular levels are presented in a healthy woman (A). Global and apical, midventricular and basal regional left ventricular rotation curves detected by threedimensional speckle-tracking echocardiography are demonstrated. In a normal case, the adequate rotational directions are counterclockwise motion of the left ventricular apex expressed with positive values and clockwise rotation of the left ventricular base with negative values $(B)$. 
4.3. Left ventricular strain reduction is not confined to the noncompacted segments in noncompaction cardiomyopathy

Patient population. The present study comprised of 9 patients with typical features of NCCM. Due to the limited image quality, one patient was excluded from the evaluations. Finally, 128 segments of 8 NCCM patients were assessed. Their results were compared to 176 segments of 11 healthy volunteers. Clinical characteristics of NCCM patients and controls are presented in Table 3.

Table 3. Clinical and two-dimensional echocardiographic characteristics of noncompaction cardiomyopathy patients and controls

\begin{tabular}{|c|c|c|}
\hline & $\begin{array}{c}\text { NCCM patients } \\
(n=8)\end{array}$ & $\begin{array}{c}\text { Controls } \\
(\mathrm{n}=11) \\
\end{array}$ \\
\hline \multicolumn{3}{|l|}{ Risk factors } \\
\hline Age (years) & $62.0 \pm 8.2$ & $60.5 \pm 7.3$ \\
\hline Male gender $(\%)$ & $3(38)$ & $2(19)$ \\
\hline Diabetes mellitus (\%) & $1(13$ & $0(0)$ \\
\hline Hypertension (\%) & $4(50)^{*}$ & $0(0)$ \\
\hline Hypercholesterolaemia (\%) & $2(25)$ & $0(0)$ \\
\hline \multicolumn{3}{|l|}{ Medications } \\
\hline$\beta$-blockers $(\%)$ & $8(100)^{*}$ & $0(0)$ \\
\hline ACE-inhibitors (\%) & $7(88)^{*}$ & $0(0)$ \\
\hline Diuretics $(\%)$ & $7(88)^{*}$ & $0(0)$ \\
\hline \multicolumn{3}{|l|}{ Two-dimensional echocardiography } \\
\hline LV end-diastolic diameter (mm) & $67.5 \pm 12.3^{*}$ & $45.8 \pm 8.4$ \\
\hline LV end-diastolic volume (ml) & $229.4 \pm 87.7^{*}$ & $101.2 \pm 44.3$ \\
\hline LV end-systolic diameter (mm) & $53.0 \pm 14.4^{*}$ & $28.0 \pm 3.5$ \\
\hline LV end-systolic volume (ml) & $141.8 \pm 73.8^{*}$ & $30.4 \pm 9.5$ \\
\hline Interventricular septum (mm) & $10.6 \pm 2.1$ & $9.7 \pm 1.6$ \\
\hline LV posterior wall (mm) & $10.0 \pm 1.5$ & $9.5 \pm 0.9$ \\
\hline LV ejection fraction $(\%)$ & $35.9 \pm 13.6^{*}$ & $68.0 \pm 6.1$ \\
\hline Number of noncompacted segments & $6.8 \pm 1.9$ & - \\
\hline
\end{tabular}

Abbreviations: ACE: angiotensin-converting enzyme, LV: left ventricular, NCCM: noncompaction cardiomyopathy.

${ }^{*} \mathrm{p}<0.0001$ vs. controls 
2D echocardiography. Standard 2D echocardiographic data are summarized in Table 3. 55 out of $128 \mathrm{LV}$ segments (43\%) proved to be noncompacted in NCCM patients, while 73 segments were compacted. The WMS index was significantly abnormal in the compacted LV segments of NCCM patients as compared to controls, and further reduction could be detected in noncompacted segments $(1.70 \pm 0.33$ vs. $2.56 \pm 0.30, p<0.05)$. Characteristics of LV wall motion contractility of noncompacted and compacted segments are reported in Table 4. No relationship was found between the number of noncompacted segments per patient and LV EF $(r=-0.06, p=0.89)$ or other $2 \mathrm{D}$ echocardiographic data.

Table 4. Comparison of wall motion characteristics of compacted and noncompacted segments in patients with noncompaction cardiomyopathy

\begin{tabular}{lccc}
\hline & $\begin{array}{c}\text { Noncompacted } \\
\text { segments } \\
(\mathbf{n}=\mathbf{5 5})\end{array}$ & $\begin{array}{c}\text { Compacted } \\
\text { segments } \\
(\mathbf{n}=\mathbf{7 3})\end{array}$ & p value \\
\hline Normokinesis (\%) & $0(0)$ & $29(40)$ & $<0.0001$ \\
Hypokinesis (\%) & $31(56)$ & $40(55)$ & 0.99 \\
Akinesis (\%) & $20(36)$ & $2(3)$ & $<0.0001$ \\
Dyskinesis (\%) & $4(7)$ & $2(3)$ & 0.40 \\
\hline
\end{tabular}

3DSTE. All strain parameters of segments of NCCM patients were significantly lower compared to controls. Only RS and 3DS showed further reduction in noncompacted segments compared to compacted segments. Other strain values were similarly lower in compacted and noncompacted segments as compared to controls (Table 5). 
Table 5. Regional three-dimensional speckle-tracking echocardiography-derived strain parameters of segments of noncompaction cardiomyopathy patients and controls

\begin{tabular}{lccc}
\hline & $\begin{array}{c}\text { Noncompacted } \\
\text { segments } \\
(\mathbf{n}=\mathbf{5 5})\end{array}$ & $\begin{array}{c}\text { Compacted } \\
\text { segments } \\
(\mathbf{n}=\mathbf{7 3})\end{array}$ & $\begin{array}{c}\text { Controls } \\
(\mathbf{n = 1 7 6})\end{array}$ \\
\hline Radial strain (\%) & $6.99 \pm 7.36^{* \dagger}$ & $12.58 \pm 12.78^{*}$ & $25.24 \pm 11.76$ \\
Longitudinal strain (\%) & $-8.06 \pm 5.21^{*}$ & $-7.82 \pm 4.19^{*}$ & $-13.07 \pm 3.89$ \\
Circumferential strain (\%) & $-11.37 \pm 5.44^{*}$ & $-10.49 \pm 6.34^{*}$ & $-21.85 \pm 2.21$ \\
Three-dimensional strain (\%) & $7.79 \pm 7.59^{*} \dagger$ & $14.67 \pm 14.04^{*}$ & $27.78 \pm 12.57$ \\
Area strain (\%) & $-18.68 \pm 8.42^{*}$ & $-16.19 \pm 8.00^{*}$ & $-29.05 \pm 14.18$ \\
\hline
\end{tabular}

$* \mathrm{p}<0.001$ vs. controls

$\dagger \mathrm{p}<0.05$ vs. compacted segments

\subsection{Comparative evaluation of left ventricular function by two-dimensional echocardiography and three-dimensional speckle-tracking echocardiography in noncompaction cardiomyopathy}

Patient population. Seven NCCM patients (average age: $62.9 \pm 8.5$ years, 3 males) were studied with 2D Doppler echocardiography and 3DSTE. Our results were compared with 10 age-, and gender-matched controls (average age: $60.7 \pm 7.7$ years, 2 males). No significant difference was detected between the two groups regarding age and gender. Classical risk factors were not present in the controls, but two NCCM patients had diabetes mellitus (28\%) and two NCCM patients had hypercholesterolaemia (28\%).

2D echocardiography vs. 3DSTE. Standard 2D echocardiography data and corresponding 3DSTE data are summarized in Table 6. Lower end-diastolic LV volume and lower LV EF were measured with 3DSTE compared with those measured with 2D echocardiography. Increased volumes and decreased EF were measured in case of NCCM in our examinations. $48(42.9 \%)$ segments of the 112 segments of the seven NCCM patients were noncompacted, and $64(57.1 \%)$ segments were compacted. There was no correlation between the number of noncompacted segments and LV EF or any other parameters measured with 2D echocardiography and $3 \operatorname{DSTE}(r=-0.03, p=0.96 ; r=0.34, p=0.45)$. 
Table 6. Two-dimensional echocardiographic and three-dimensional speckle-tracking echocardiographic data of the studied patient groups

\begin{tabular}{lllll}
\hline & \multicolumn{2}{c}{ NCCM patients } & \multicolumn{2}{c}{ Controls } \\
& 2DE & 3DSTE & 2DE & 3DSTE \\
\hline LV EDD (mm) & $68.2 \pm 13.1^{*}$ & - & $46.5 \pm 8.6$ & - \\
LV EDV (ml) & $233.9 \pm 93.7^{* \dagger}$ & $205.1 \pm 58.2^{* \dagger} \dagger$ & $104.6 \pm 45.1 \dagger$ & $71.8 \pm 14.1$ \\
LV ESD (mm) & $54.1 \pm 15.2^{*}$ & - & $28.2 \pm 3.7$ & - \\
LV ESV (m) & $148.8 \pm 76.8^{* \dagger}$ & $151.8 \pm 35.9^{* \dagger} \dagger$ & $30.8 \pm 9.9$ & $29.7 \pm 2.6$ \\
IVS (mm) & $10.4 \pm 2.2$ & - & $9.9 \pm 1.6$ & - \\
LV PW (mm) & $10.0 \pm 1.6$ & - & $9.5 \pm 1.0$ & - \\
LV EF (\%) & $33.4 \pm 12.6^{* \dagger}$ & $24.7 \pm 9.5^{* \dagger}$ & $68.8 \pm 6.0 \dagger$ & $56.9 \pm 8.3$ \\
\hline
\end{tabular}

Abbreviations: $2 \mathrm{DE}=$ two-dimensional echocardiography; $3 \mathrm{DSTE}=$ three-dimensional speckle-tracking echocardiography; $\mathrm{LV}=$ left ventricle; $\mathrm{NCCM}=$ noncompaction cardiomyopathy. EDD: end-diastolic diameter, EDV: end-diastolic volume, ESD: end-systolic diameter, ESV: end-systolic volume, IVS: Interventricular septum, PW: posterior wall, EF: ejection fraction

$* \mathrm{p}<0.05$ vs. $2 \mathrm{DE}$ (controls)

$\dagger \mathrm{p}<0.05$ vs. 3DSTE (controls)

Strain parameters calculated with 3DSTE. The average value of strain parameters of all segments of NCCM patients was significantly decreased compared with the control value irrespective of whether the segment was compacted or not (Table 7). RS and 3DS showed further decrease in case of noncompacted segments compared with compacted segments. 
Table 7. Strain and rotation parameters measured with three-dimensional speckletracking echocardiography in noncompaction cardiomyopathy and in controls

\begin{tabular}{lccc}
\hline & $\begin{array}{c}\text { Noncompacted } \\
\text { segments } \\
(\mathbf{n = 4 8 )}\end{array}$ & $\begin{array}{c}\text { Compacted } \\
\text { segments } \\
(\mathbf{n = 6 4 )}\end{array}$ & $\begin{array}{c}\text { Controls } \\
\mathbf{( n = 1 6 0 )}\end{array}$ \\
\hline Radial strain (\%) & $7.5 \pm 7.5^{* \dagger}$ & $13.3 \pm 13.3^{*}$ & $25.1 \pm 13.7$ \\
Longitudinal strain (\%) & $-8.1 \pm 4.0^{*}$ & $-8.0 \pm 4.0^{*}$ & $-12.8 \pm 7.00$ \\
Circumferential strain (\%) & $-11.3 \pm 5.6^{*}$ & $-11.3 \pm 6.1^{*}$ & $-21.1 \pm 11.3$ \\
Three-dimensional strain (\%) & $8.1 \pm 7.8^{*} \dagger$ & $15.5 \pm 14.6^{*}$ & $27.7 \pm 14.8$ \\
Area strain (\%) & $-18.5 \pm 8.4^{*}$ & $-17.2 \pm 7.3^{*}$ & $-27.7 \pm 15.6$ \\
\hline
\end{tabular}

$* \mathrm{p}<0.05$ vs. controls

$\dagger \mathrm{p}<0.05$ vs. compacted segments

Rotational parameters calculated with 3DSTE. Rotational parameters calculated with 3DSTE confirmed the fact that the basal and apical segments of the LV move towards the same direction in NCCM in all cases, that is the real twist is absent. Counterclockwise rotation of the LV was confirmed in five cases, and clockwise rotation was found in two cases. In both cases, the extent of twisting was significantly decreased compared with the control values (Table 8).

Table 8. Rotational and twist parameters with three-dimensional speckle-tracking echocardiography in noncompaction cardiomyopathy and in controls

\begin{tabular}{|c|c|c|}
\hline \multicolumn{2}{|c|}{ NCCM patients } & Controls \\
\hline $\begin{array}{c}\text { Rotation in } \\
\text { counterclockwise } \\
\text { direction } \\
(\mathrm{n}=5) \\
\end{array}$ & $\begin{array}{l}\text { Rotation in } \\
\text { clockwise } \\
\text { direction } \\
(\mathrm{n}=2) \\
\end{array}$ & $(\mathrm{n}=5)$ \\
\hline $3.61 \pm 3.59 * \dagger$ & $-4.10 \pm 1.12$ & $-2.54 \pm 2.10$ \\
\hline $8.18 \pm 5.90^{*}$ & $-6.44 \pm 5.64 \dagger$ & $8.25 \pm 1.37$ \\
\hline $5.50 \pm 4.21 * \dagger$ & $-2.58 \pm 2.74 \dagger$ & $10.81 \pm 2.01$ \\
\hline
\end{tabular}

$* p<0.05$ vs. rotation in clockwise direction (NCCM)

$\dagger \mathrm{p}<0.05$ vs. controls 


\subsection{Quantification of changes in septal strain after alcohol septal ablation in hypertrophic obstructive cardiomyopathy}

Case study 1. A case of a 55-year-old male patient with obstructive HCM undergoing alcohol septal ablation is presented. Typical asymmetric septal hypertrophy with thickened interventricular septum (maximal end-diastolic thickness [MEDT]: $24 \mathrm{~mm}$ ) was confirmed with transthoracic 2D echocardiography. Resting peak LV outflow tract (LVOT) gradient was $88 \mathrm{mmHg}$, which increased to $118 \mathrm{mmHg}$ during Valsalva manoeuvre. Regarding the symptoms and NYHA III functional class of the patient (shortness of breath, perspiration, chest pain, palpitations), PTSMA was performed according to established protocols. The first septal branch was selected for ablation which was occluded by $2 \times 10 \mathrm{~mm}$ over the wire PCI balloon, and contrast echocardiography was performed. Contrast accumulation was detected only in the hypertrophied part of the septum involving the site of septum-anterior mitral leaflet contact. Two $\mathrm{ml}$ alcohol was injected slowly into the septal branch, during which no ventricular arrhythmia or AV block was detected. Post-procedural resting peak LVOT gradient was $28 \mathrm{mmHg}$ and a rise of $839 \mathrm{U} / 1$ in creatine kinase (CK) value (normal range: $<195 \mathrm{U} / \mathrm{l})$ was observed.

3DSTE was performed 1 day before and 3 days after PTSMA to quantify changes in septal strain of the ablated area. Strain curves of basal, midventricular and apical septum are presented in Figures 9 and 10. RS and CS (Figure 9) and LS and 3DS (Figure 10) curves showed significant changes in basal segments of the septum (see white arrows). 
Radial Strain

Circumferential Strain
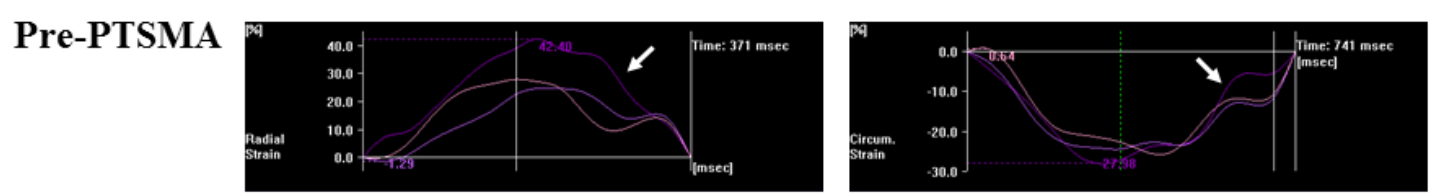

Post-PTSMA
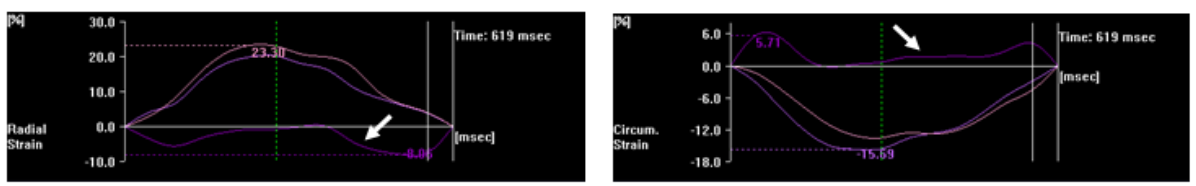

Figure 9. Radial and circumferential strain curves of the basal, midventricular and apical septum are presented 1 day before and 3 days after percutaneous transluminal septal myocardial ablation in a patient with hypertrophic obstructive cardiomyopathy. White arrows are demonstrating changes in strain values of the basal septum.

Abbreviation: PTSMA: percutaneous transluminal septal myocardial ablation

Longitudinal Strain

3D Strain
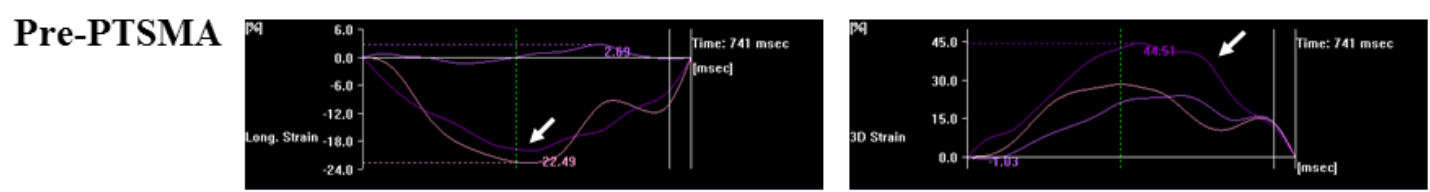

Post-PTSMA
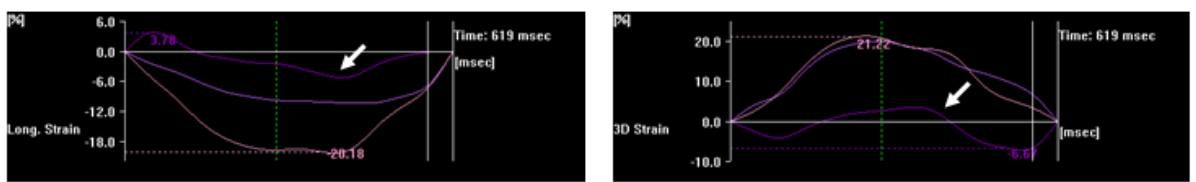

Figure 10. Longitudinal and 3D strain curves of the basal, midventricular and apical septum are presented 1 day before and 3 days after percutaneous transluminal septal myocardial ablation in a patient with hypertrophic obstructive cardiomyopathy. White arrows are demonstrating changes in strain values of the basal septum.

Abbreviation: PTSMA: percutaneous transluminal septal myocardial ablation 
Post-procedural cardiac magnetic resonance imaging confirmed scar formation in the targeted septal area (Figure 11).

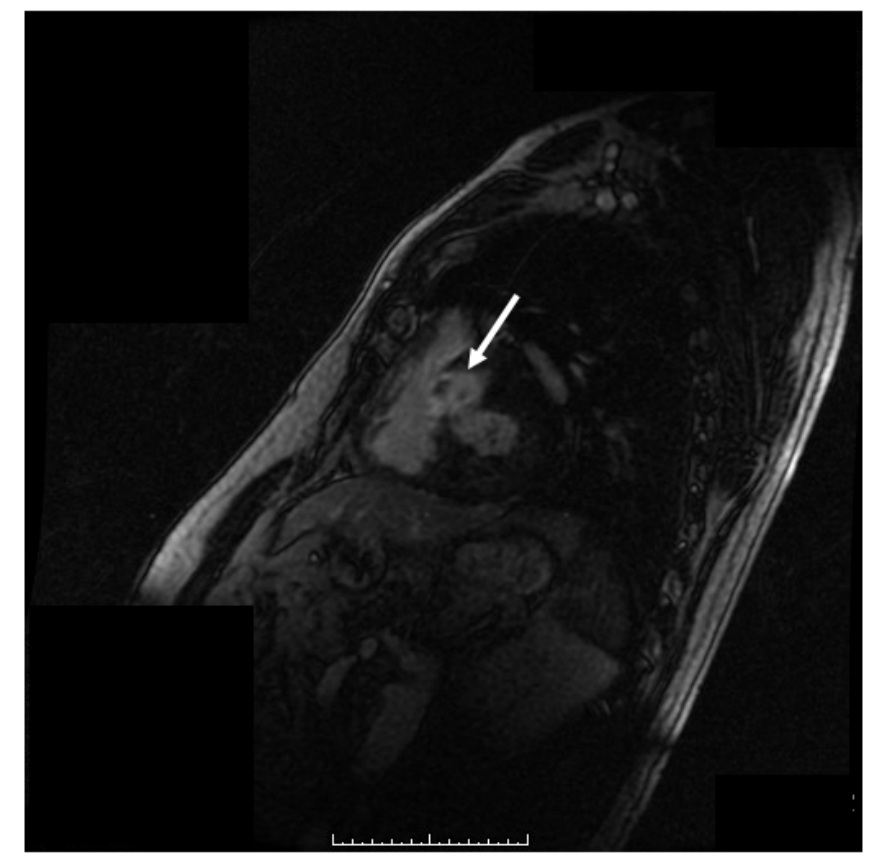

Figure 11. Postprocedural magnetic resonance imaging confirmed scar formation in the targeted septal area. White arrow demonstrates infarction of the basal segment of the septum.

Case study 2. A 62-year-old male patient with combined aortic stenosis and obstructive HCM undergoing PTSMA is presented. Due to significant aortic stenosis (mean aortic gradient: 57 $\mathrm{mmHg}$, LVOT gradient: $35 \mathrm{mmHg}$ ), aortic valve replacement with a mechanical valve (Carpentier-Edwards Peirmount A-21 mm) was successfully performed 18 months before PTSMA. Effort dyspnea persisted after the operation, therefore control echocardiography was performed that showed $18 \mathrm{mmHg}$ valvular gradient and $68 \mathrm{mmHg}$ subvalvular LVOT gradient (septal MEDT: $24 \mathrm{~mm}$ ). During semi-supine stress treadmill test, $61 \mathrm{mmHg}$ resting LVOT gradient increased to $108 \mathrm{mmHg}$. During PTSMA, the first septal branch was ablated after contrast echocardiography which showed contrast accumulation only in the basal septum. Post-procedural resting peak LVOT gradient was $27 \mathrm{mmHg}$ and a CK rise of $499 \mathrm{U} / 1$ was noted. 3DSTE-derived strain parameters showed similar alterations following PTSMA as in Case 1. 


\section{Discussion}

\subsection{Correlations between echocardiographic aortic elastic properties and left ventricular rotation and twist}

To the best of authors' knowledge, this is the first study in which relationship between 3DSTE-derived LV rotational and twist parameters and echocardiographic aortic elastic properties were examined. Significant correlations could be demonstrated between LV rotational mechanics and aortic elasticity parameters in a healthy population.

The LV twist is the result of the movement of two orthogonally oriented mascular bands of a helical myocardial structure with consequent clockwise rotation of the LV base and counterclockwise rotation of the LV apex $(22,40,41)$. LV twist is suggested as an important index of contractility and aids in generating suction power in early diastole (41-43). According to Nakatani, rotation and twist is governed by the following main factors (42):

- $\quad$ the degree of contraction and relaxation of the myocardium

- $\quad$ the balance between contraction of the subendocardium and subepicardium

- $\quad$ orientation of the myocardial fibers

Moreover, there are some other physiological variables influencing LV twist mechanics: LV twist is greater with higher preload, increasing with LV contractility, exercise and together with age, but LV twist is lower with higher afterload (41).

3DSTE is a non-invasive, simple and easy-to-learn tool which is based on tracking and measurement of tissue displacement in the 3D space (26). It has just been introduced and has been developed to reduce some shortcomings of the 2DSTE (44). In a recent study, 3DSTE was found to be feasible for the assessment of LV rotational and twist parameters (45). However, limited number of papers is available analyzing LV rotational and twist parameters by 3DSTE currently. 3DSTE showed relatively lower reproducibility and slightly better accuracy compared with the 2DSTE (21). Urbano-Moral et al. have demonstrated that patients with hypertrophic cardiomyopathy show increased peak LV twist which is mainly dependent on the apical rotation of those with LV outflow tract obstruction, onset of torsion recoil occurring close to the aortic valve closure, limited completion of untwist during early diastole, and delayed peak untwist velocity (22).

Aortic stiffening is a common feature of human aging and is exacerbated by different disorders (24). Aortic stiffening may contribute to pathological changes in the LV by 
increasing central aortic SBP, decreasing central aortic DBP, therefore increasing LV afterload. Increased LV afterload may promote LV hypertrophy, impair LV relaxation leading to LV diastolic dysfunction. Reduction in DBP may compromise coronary perfusion leading to subendocardial ischaemia (24). However, its effect on LV wringing motion has not been widely investigated.

There are several ways to characterize aortic stiffness including analysis of pulse waves (measurement of pulse wave velocity) or calculating a parameter in which two important variables is noted: the change in volume due to blood injection in the aorta (measurement of DS and DD), and the pressure change caused by this volume change (measurement of SBP and DBP) (25). Several echocardiographic aortic elastic properties could be calculated including aortic strain, distensibility and stiffness index using these values.

The current study aimed to assess the relationship between echocardiographic aortic elastic properties and 3DSTE-derived LV rotation and twist. Aortic stiffness index showed significant positive correlations with apical LV rotation and LV twist suggesting that higher aortic stiffness is associated with larger apical LV rotation and LV twist, even in healthy subjects. Aortic distensibility had a significant negative correlation with apical LV rotation confirming these findings. These results could suggest a compensatory increase in LV twisting against increasing aortic stiffness. However, further studies are warranted with other methods confirming our findings, even in healthy volunteers. In conclusion, correlations exist between aortic elastic properties and left ventricular rotation and twist in healthy subjects.

Study limitations. However, some important limitations should be taken into consideration analyzing our results:

(1) The blood pressure measured in the brachial artery may be different from the pressures in the ascending aorta, due to pulse pressure amplification towards the periphery. However, the results obtained by the echocardiographic method used correlate well with those from invasive methods (39).

(2) 3DSTE is a novel clinical procedure the validation of which is in progress, and therefore it is not complete, additional examinations are required.

(3) Temporal resolution of 3D acquisition for speckle-tracking analysis is low as compared to 2D echocardiography, which can affect the good tracking of speckles. Moreover, to achieve rapid frame or volume rates, the 3D sector angle must be reduced in most of cases which could aggravate the evaluation of the $\operatorname{LV}(22,46)$. 
(4) This was a single-centre experience and limited by a relatively small number of healthy volunteers. The study would have been statistically stronger, if larger number of subjects had been evaluated.

(5) Due to the fact that little is known about the factors affecting rotational mechanics of the heart, heterogeneity of the population, including etiological parameters (age, gender etc.) could also affect the results (46).

(6) It was not aimed to evaluate the relationship between other characteristics of LV systolic and diastolic function and aortic elasticity parameters in this healthy population.

\subsection{Identification of left ventricular 'rigid body rotation' by three-dimensional speckle- tracking echocardiography in a patient with noncompaction of the left ventricle}

LV twist is defined as the net difference between apical and basal rotation values as described above. STE could show dynamics, magnitudes and timing of LV rotation and torsion mechanics independently of both cardiac translation and beam angle. STE is based on frame-by-frame tracking of speckle patterns created by interference of the ultrasound beam within the myocardial tissue. 2DSTE has been validated against sonomicrometry and tagged magnetic resonance imaging to assess LV twist (47). However, 2DSTE has several limitations including to be affected by the use of foreshortened apical views and geometric assumptions. Moreover, there is a limited ability to track motion occurring within the imaging plane due to 3D motion of the cardiac tissue (48). 3DSTE has just been introduced, and found to be an accurate method for the evaluation of LV rotation mechanics (49). Andrade et al. found 3DSTE to be feasible to assess LV rotation and therefore twist deformation (45). In a recent study using 2DSTE, LV basal and LV apical rotations were in the same direction with near absence of LV twist in NCCM patients (33). Moreover, this 'rigid body rotation' was found to be an objective, quantitative, and reproducible functional criterion with good predictive value for the diagnosis of NCCM (50). To the best of authors' knowledge this is the first time confirming LV 'rigid body rotation' in an NCCM patient by 3DSTE. 


\subsection{Left ventricular strain reduction is not confined to the noncompacted segments in noncompaction cardiomyopathy}

In the present study, it was aimed to evaluate different contributions of noncompacted and compacted segments to the global LV systolic dysfunction in NCCM patients by 3DSTE. To the best of authors' knowledge, this is the first time when 3DSTE-derived strain parameters were analyzed in cases with typical features of NCCM. All 3DSTE-derived strain parameters proved to be significantly decreased in all segments of NCCM patients as compared to segments of controls. Moreover, RS and 3DS showed further reduction in noncompacted segments compared to compacted segments in NCCM patients.

NCCM is a new pathoanatomic entity, disputably believed to result from abnormal arrest in embryonic endomyocardial morphogenesis (51). Our understanding of NCCM is limited, only few studies are available evaluating contributions of noncompacted and compacted segments to the global LV dysfunction. In a recent study, results of Lofiego et al. suggested that noncompacted and compacted LV segments provide different contributions to overall systolic LV dysfunction (52). In another volumetric RT3DE study, noncompacted and compacted LV segments had comparably increased regional volumes and reduced systolic function suggesting that systolic LV dysfunction in NCCM is not confined to the noncompacted segments (34).

Recently, LV myocardial deformation was found to be decreased in the longitudinal and circumferential dimensions by 2DSTE in NCCM children (53). Moreover, most accurate speckle myocardial imaging modalities to discriminate between NCCM patients and controls were longitudinal systolic strain of the six apical segments, LV apical rotation and LV torsion rate (54). Our results are partially in agreement with these findings, but 3DSTE allowed more detailed insights into pathophysiology of NCCM demonstrating alterations in all 'simple' and 'complex' strain parameters.

3DSTE uses a different 3D speckle tracking-based method to assess cardiac volumes when compared to direct volumetric RT3DE (55). However, only a limited number of 3DSTE studies are available in which NCCM patients were examined currently $(56,57)$. Results of the present study could draw attention to the quantitative evaluation of wall motion abnormalities by 3DSTE-derived strain analysis, especially in special cardiomyopathies. In conclusion, left ventricular strain reduction is not confined to the noncompacted segments in noncompaction cardiomyopathy. Radial strain and 3D strain parameters show further reduction in noncompacted segments compared to compacted segments. 
Study limitations. However, some important factors should be taken into consideration analyzing our results in addition to the above mentioned limitations:

(1) Due to the nature of noncompacted myocardium with a very difficult fiber orientation, calculation of regional deformation is very difficult, which should always be taken into account during evaluations.

(2) This study did not evaluate 3DSTE-derived rotational and twist parameters $(22,41)$.

(3) The normal range of different strain parameters has not been clarified in the literature because the values vary by vendor. Our results are similar to other studies and the lower rate of RS may be due to different technology (59).

\subsection{Comparative evaluation of left ventricular function by two-dimensional echocardiography and three-dimensional speckle-tracking echocardiography in noncompaction cardiomyopathy}

NCCM is often accompanied by LV dysfunction or heart failure, and the treatment of malignant arrhythmias and thromboembolic events may pose serious problems as well. The potential role of compacted and noncompacted segments in the development of LV dysfunction in NCCM is an important question.

Currently, there are few publications about 3DSTE studies of NCCM patients, but the number of publications is expected to increase regarding the spreading of the method and the increasing number of patients diagnosed with $\operatorname{NCCM}(56,57)$.

In our examinations, higher LV volumes and lower EF were measured in NCCM. End-diastolic volumes measured with 3DSTE were lower compared with $2 \mathrm{D}$ echocardiography, while end-systolic values were similar. This may have been the reason for lower EF values measured with 3DSTE measurements. Parameters measured with 3DSTE were primarily compared with results of magnetic resonance studies before with proper inter- and intra-observer variability; although volumes were lower in those studies as well (48, $60,61)$.

3DSTE is suitable for determining volumetric data as well as for quantitatively characterizing global and regional wall motions $(6,58,62-64)$. This method can be used to determine numeric strain parameters regarding the whole LV and to characterize contractionrelaxation of certain segments as demonstrated in the previous chapter $(5.3)(6,62-64)$. In accordance with 3D movement-contraction of the LV, three different 'standard' strain 
parameters are differentiated: RS (radial shortening), LS (longitudinal shortening) and CS (cross-sectional shortening) (58). In addition, two combined strain parameters can also be calculated with 3DSTE: AS (combination of longitudinal and circumferential shortening, tracking a rectangular-shaped area in 3D throughout the heart cycle) and 3DS (combination of the three 'standard' strain parameters) (58). Our results confirmed that all above listed strain parameters were significantly different in case of NCCM in compacted and noncompacted segments as well. RS and 3DS were further reduced in the noncompacted segments. These results may draw attention to the fact that not only the noncompacted segments can be responsible for LV dysfunction in NCCM. Our results are in line with a previous RT3DE study where similarly increased segmental LV volumes and decreased segmental EF were found in compacted and noncompacted segments in NCCM (34).

In healthy adult hearts, the basal segment of the LV rotates in clockwise direction in systole, while the apex moves in counter-clockwise direction (65), this movement is called twisting. 3DSTE was found to be a suitable method for the quantitative measurement of twisting $(45,49)$. While counter-clockwise apical rotation does not change with age, the direction of basal rotation changes from counter-clockwise direction seen in infants to clockwise rotation in adults (41). Based on previous 2DSTE studies, it was suggested that twist is absent in NCCM, the LV 'rotates' as a rigid body (66). This movement was called 'rigid body rotation' in the English literature, its prognostic value was confirmed as well (50). We have confirmed this movement in an NCCM patient with 3DSTE before in a case report (57, and chapter 5.2). In our present study, rigid body rotation could be confirmed in all of our patients. It seems that changes in basal rotation with age were absent in the majority of our NCCM patients, and the direction of basal rotation remained counter-clockwise. Interestingly, basal and apical rotations occurred in clockwise direction in two cases. In conclusion, left ventricular function and contractility of the left ventricular segments are significantly decreased in noncompaction cardiomyopathy. Left ventricular twist is missing in NCCM.

Study limitations. However, some important limitations should be taken into consideration analyzing our results in addition to the above mentioned limitations:

(1) Orientation of myocardial fibers in an NCCM heart is complicated and it is not completely known yet, which makes calculation of strain, rotational and twist parameters more difficult.

(2) Defining the LV cavity may be more difficult in NCCM due to the trabeculations. In our practice, all recesses are considered to be cavities with $100 \% \mathrm{EF}$, therefore the 
cavities of the recesses are not considered when defining the edge of the LV endocardium.

(3) Strain parameters of controls may be lower than literature data, it is the consequence of the basics of 3DSTE, the exact explanation for this is not known yet (59).

(4) The aim of our current study was to examine the LV, although 3DSTE may be a suitable method to analyze the atria or even the right ventricle as well.

(5) Based on currently available information, LV dyssynchrony can also be characterized with 3DSTE, but literature data is limited and not consistent, therefore it was not examined in our current study.

\subsection{Quantification of changes in septal strain after alcohol septal ablation in hypertrophic obstructive cardiomyopathy}

The results of our cases could suggest the possible role of 3DSTE in the quantitative evaluation of the success of PTSMA. At this moment, there are only a few number of studies in which STE was used for LV strain assessments in HCM. Despite apparently normal left ventricular systolic function, all components of 2DSTE-derived strain were significantly reduced in a subset of patients with familial nonobstructive HCM (67). In contrast, HCM patients had higher circumferential and lower longitudinal strain compared with control subjects using 2D velocity vector imaging in another study (68). Moreover, Reddy et al. reported 2 cases of apical HCM in which 2DSTE revealed paradoxical longitudinal strain (systolic lengthening) in the apical segments (69).

3DSTE is a new methodology trying to summarize advantages of both $3 \mathrm{D}$ echocardiography and STE. 3DSTE can measure all rotational and strain parameters of all LV segments from a single acquisition (69). Moreover, 3DSTE is an angle independent tool, and do not suffer from strain estimation errors associated with out-of-plane motion suggesting more precise calculations (70). 3DSTE enables the examiner to identify the longest LV diameter in 2 long-axis images perpendicular to each other, thus avoiding foreshortening of the LV (71). However, at this moment 3DSTE depends on the quality of 2D images used for acquisition and suffers in lower spatial and temporal resolution $(69,70,72)$.

To the best of authors' knowledge this is the first time to examine the changes of 3DSTE-derived strain parameters following successful PTSMA in obstructive HCM patients. At this moment it is not obvious how this method will change the management or prognostication of PTSMA. However, results could highlight our attention on the 
quantification of the success of PTSMA by the above mentioned 3DSTE-derived strain parameters, but further studies are warranted in series of obstructive HCM patients. 
Correlations exist between echocardiographic aortic elastic properties and 3DSTE-derived LV rotation and twist in healthy subjects.

3DSTE seems to be a reliable method to confirm LV rigid body rotation in NCCM.

Left ventricular strain reduction is not confined to the noncompacted segments in noncompaction cardiomyopathy. Radial and 3D strain parameters show further reduction in noncompacted segments compared to compacted segments.

High prevalence of the absence of LV twist (LV "rigid body rotation") could be demonstrated in a series of NCCM patients.

The possible role of 3DSTE is suggested in the quantitative evaluation of the success of PTSMA by strain analysis. 


\section{References}

1. Toyoda T, Baba H, Akasaka T, Akiyama M, Neishi Y, Tomita J, Sukmawan R, Koyama Y, Watanabe N, Tamano S, Shinomura R, Komuro I, Yoshida K. Assessment of regional myocardial strain by a novel automated tracking system from digital image files. J Am Soc Echocardiogr. 2004;17(12):1234-8.

2. Leitman M, Lysyansky P, Sidenko S, Shir V, Peleg E, Binenbaum M, Kaluski E, Krakover R, Vered Z. Two-dimensional strain-a novel software for real-time quantitative echocardiographic assessment of myocardial function. J Am Soc Echocardiogr. 2004; 17(10):1021-9.

3. Amundsen BH, Helle-Valle T, Edvardsen T, Torp H, Crosby J, Lyseggen E, Støylen A, Ihlen H, Lima JA, Smiseth OA, Slørdahl SA. Noninvasive myocardial strain measurement by speckle tracking echocardiography: validation against sonomicrometry and tagged magnetic resonance imaging. J Am Coll Cardiol. 2006; 47(4):789-93.

4. Korinek J, Wang J, Sengupta PP, Miyazaki C, Kjaergaard J, McMahon E, Abraham TP, Belohlavek M. Two-dimensional strain--a Doppler-independent ultrasound method for quantitation of regional deformation: validation in vitro and in vivo. $\mathrm{J}$ Am Soc Echocardiogr. 2005; 18(12):1247-53.

5. Edvardsen T, Gerber BL, Garot J, Bluemke DA, Lima JA, Smiseth OA. Quantitative assessment of intrinsic regional myocardial deformation by Doppler strain rate echocardiography in humans: validation against three-dimensional tagged magnetic resonance imaging. Circulation. 2002; 106(1):50-6.

6. Seo Y, Ishizu T, Enomoto Y, Sugimori H, Yamamoto M, Machino T, Kawamura R, Aonuma K. Validation of 3-dimensional speckle tracking imaging to quantify regional myocardial deformation. Circ Cardiovasc Imaging. 2009; 2(6):451-9.

7. Støylen A, Heimdal A, Bjørnstad K, Wiseth R, Vik-Mo H, Torp H, Angelsen B, Skjaerpe T. Strain rate imaging by ultrasonography in the diagnosis of coronary artery disease. J Am Soc Echocardiogr. 2000; 13: 1053-64.

8. Urheim S, Edvardsen T, Torp H, Angelsen B, Smiseth OA. Myocardial strain by Doppler echocardiography: validation of a new method to quantify regional myocardial function. Circulation. 2000; 102: 1158-64. 
9. Sutherland GR, Di Salvo G, Claus P, D'hooge J, Bijnens B. Strain and strain rate imaging: a new clinical approach to quantifying regional myocardial function. J Am Soc Echocardiogr. 2004; 17: 788-802.

10. Becker M, Hoffmann R, Kühl HP, Grawe H, Katoh R, Kramann R, Bücker A, Hanrath P, Heussen N. Analysis of myocardial deformation based on ultrasonic pixel tracking to determine transmurality in chronic myocardial infarction. Eur Heart J. 2006; 27: 2560-6.

11. Wang J, Khoury DS, Yue Y, Torre-Amione G, Nagueh SF. Preserved left ventricular twist and circumferential deformation, but depressed longitudinal and radial deformation in patients with diastolic heart failure. Eur Heart J. 2008; 29: 1283-9.

12. Suffoletto MS, Dohi K, Cannesson M, Saba S, Gorcsan J III. Novel speckletracking radial strain from routine black-and-white echocardiographic images to quantify dyssynchrony and predict response to cardiac resynchronization therapy. Circulation. 2006; 113: 960-8.

13. Delgado V, Ypenburg C, van Bommel RJ, Tops LF, Mollema SA, Marsan NA, Bleeker GB, Schalij MJ, Bax JJ. Assessment of left ventricular dyssynchrony by speckle tracking strain imaging comparison between longitudinal, circumferential, and radial strain in cardiac resynchronization therapy. J Am Coll Cardiol. 2008; 51: $1944-52$.

14. Jenkins C, Bricknell K, Hanekom L, Marwick TH. Reproducibility and accuracy of echocardiographic measurements of left ventricular parameters using real-time three-dimensional echocardiography. J Am Coll Cardiol. 2004; 44: 878-86.

15. Kühl HP, Schreckenberg M, Rulands D, Katoh M, Schäfer W, Schummers G, Bücker A, Hanrath P, Franke A. High-resolution transthoracic real-time threedimensional echocardiography: quantitation of cardiac volumes and function using semi-automatic border detection and comparison with cardiac magnetic resonance imaging. J Am Coll Cardiol. 2004; 43: 2083-90.

16. Sugeng L, Mor-Avi V, Weinert L, Niel J, Ebner C, Steringer-Mascherbauer R, Schmidt F, Galuschky C, Schummers G, Lang RM, Nesser HJ. Quantitative assessment of left ventricular size and function: side-by-side comparison of realtime three-dimensional echocardiography and computed tomography with magnetic resonance reference. Circulation. 2006; 114: 654-61. 
17. Mor-Avi V, Sugeng L, Weinert L, MacEneaney P, Caiani EG, Koch R, Salgo IS, Lang RM. Fast measurement of left ventricular mass with real-time threedimensional echocardiography: comparison with magnetic resonance imaging. Circulation. 2004; 110: 1814-18.

18. Takeuchi M, Nishikage T, Mor-Avi V, Sugeng L, Weinert L, Nakai H, Salgo IS, Gerard O, Lang RM. Measurement of left ventricular mass by real-time threedimensional echocardiography: validation against magnetic resonance and comparison with two-dimensional and m-mode measurements. J Am Soc Echocardiogr. 2008; 21: 1001-5.

19. Kapetanakis S, Kearney MT, Siva A, Gall N, Cooklin M, Monaghan MJ. Real-time three-dimensional echocardiography: a novel technique to quantify global left ventricular mechanical dyssynchrony. Circulation. 2005; 112: 992-1000.

20. Nemes A, Kalapos A, Domsik P, Forster T. Three-dimensional speckle-tracking echocardiography -- a further step in non-invasive three-dimensional cardiac imaging. Orv Hetil. 2012; 153(40):1570-7.

21. Ashraf M, Zhou Z, Nguyen T, Ashraf S, Sahn DJ. Apex to base left ventricular twist mechanics computed from high frame rate two-dimensional and threedimensional echocardiography: a comparison study. J Am Soc Echocardiogr. 2012; 25(1):121-8.

22. Urbano Moral JA, Arias Godinez JA, Maron MS, Malik R, Eagan JE, Patel AR, Pandian NG. Left ventricular twist mechanics in hypertrophic cardiomyopathy assessed by three-dimensional speckle tracking echocardiography. Am J Cardiol. 2011; 108(12):1788-95.

23. Shim CY. Arterial-cardiac interaction: the concept and implications. J Cardiovasc Ultrasound. 2011; 19(2):62-6.

24. Belz GG. Elastic properties and Windkessel function of the human aorta. Cardiovasc Drugs Ther. 1995; 9(1):73-83.

25. Nemes A, Geleijnse ML, Forster T, Soliman OI, Ten Cate FJ, Csanady M. Echocardiographic evaluation and clinical implications of aortic stiffness and coronary flow reserve and their relation. Clin Cardiol 2008; 31:304-9.

26. Ammar KA, Paterick TE, Khandheria BK, Jan MF, Kramer C, Umland MM, Tercius AJ, Baratta L, Tajik AJ. Myocardial mechanics: understanding and applying three-dimensional speckle tracking echocardiography in clinical practice. Echocardiography. 2012; 29(7):861-72. 
27. Chin TK, Perloff JK, Williams RG, Jue K, Mohrmann R. Isolated noncompaction of left ventricular myocardium. A study of eight cases. Circulation. 1990; 82(2), $507-13$.

28. Jenni R, Oechslin E, Schneider J, Attenhofer Jost C, Kaufmann PA. Echocardiographic and pathoanatomical characteristics of isolated left ventricular non-compaction: a step towards classification as a distinct cardiomyopathy. Heart 2001; 86(6):666-71.

29. Nemes A, Geleijnse ML, Caliskan K, Soliman OI, Vletter WB, Forster T, ten Cate FJ. How can real-time 3-dimensional echocardiography help in the evaluation of noncompaction cardiomyopathy? [Miben tud segíteni a real-time 3-dimenziós echokardiográfia a noncompaction cardiomyopathia vizsgálatában?] Cardiol. Hung. 2009; 39: 236-40.

30. Rosa LV, Salemi VM, Alexandre LM, Mady C. Noncompaction cardiomyopathy: a current view. Arq Bras Cardiol. 2011; 97(1):e13-9.

31. Lengyel, M.: Isolated left ventricular noncompaction - first description in a Hungarian patient. [Izolált bal kamrai non-kompakció (szivacsos myocardium): első hazai leírás.] Orv. Hetil., 2002, 143, 1651-1653.

32. Szabó Z, Pinczés I, Vágó H. Isolated left ventricular noncompaction cardiomyopathy. [Izolált bal kamrai non-kompakt cardiomyopathia.] Cardiol Hung. 2009; 39: 20-6.

33. van Dalen BM, Caliskan K, Soliman OI, Nemes A, Vletter WB, Ten Cate FJ, Geleijnse ML. Left ventricular solid body rotation in non-compaction cardiomyopathy: a potential new objective and quantitative functional diagnostic criterion? Eur J Heart Fail. 2008; 10:1088-93.

34. Nemes A, Caliskan K, Geleijnse ML, Soliman OI, Vletter WB, ten Cate FJ. Reduced regional systolic function is not confined to the noncompacted segments in noncompaction cardiomyopathy. Int J Cardiol. 2009; 134(3):366-70.

35. Maron BJ. Hypertrophic cardiomyopathy: a systematic review. JAMA 2002; 287: 1308-1320.

36. Roşca M, Popescu BA, Beladan CC, Călin A, Muraru D, Popa EC, Lancellotti P, Enache R, Coman IM, Jurcuţ R, Ghionea M, Ginghină C. Left atrial dysfunction as a correlate of heart failure symptoms in hypertrophic cardiomyopathyJ Am Soc Echocardiogr. 2010; 23(10):1090-8. 
37. Baccouche H, Maunz M, Beck T, Gaa E, Banzhaf M, Knayer U, Fogarassy P, Beyer M. Differentiating cardiac amyloidosis and hypertrophic cardiomyopathy by use of three-dimensional speckle tracking echocardiography. Echocardiography 2012; 29:668-77.

38. Authors/Task Force members, Elliott PM, Anastasakis A, Borger MA, Borggrefe M, Cecchi F, Charron P, Hagege AA, Lafont A, Limongelli G, Mahrholdt H, McKenna WJ, Mogensen J, Nihoyannopoulos P, Nistri S, Pieper PG, Pieske B, Rapezzi C, Rutten FH, Tillmanns C, Watkins H. 2014 ESC Guidelines on diagnosis and management of hypertrophic cardiomyopathy: the Task Force for the Diagnosis and Management of Hypertrophic Cardiomyopathy of the European Society of Cardiology (ESC). Eur Heart J. 2014 Oct 14;35(39):2733-79.

39. Stefanadis C, Stratos C, Boudoulas H, Kourouklis C, Toutouzas P. Distensibility of the ascending aorta: comparison of invasive and non-invasive techniques in healthy men and in men with coronary artery disease. Eur Heart J. 1990; 11(11):990-6.

40. Kocica MJ, Corno AF, Carreras-Costa F, Ballester-Rodes M, Moghbel MC, Cueva CN, Lackovic V, Kanjuh VI, Torrent-Guasp F. The helical ventricular myocardial band: global, three-dimensional, functional architecture of the ventricular myocardium. Eur J Cardiothorac Surg. 2006; 29 Suppl 1:S21-40.

41. Sengupta PP, Tajik AJ, Chandrasekaran K, Khandheria BK. Twist mechanics of the left ventricle: principles and application. JACC Cardiovasc Imaging. 2008; $1(3): 366-76$.

42. Nakatani S. Left ventricular rotation and twist: why should we learn? J Cardiovasc Ultrasound. 2011; 19(1):1-6.

43. Notomi Y, Popovic ZB, Yamada H, Wallick DW, Martin MG, Oryszak SJ, Shiota T, Greenberg NL, Thomas JD. Ventricular untwisting: a temporal link between left ventricular relaxation and suction. Am J Physiol Heart Circ Physiol. 2008; 294(1):H505-13.

44. Abe Y, Kawagishi T, Ohuchi H, Takeguchi T, Nishiura M. Accurate detection of regional contraction using novel 3-dimensional speckle tracking technique. J Am Coll Cardiol 2008;51:A116.

45. Andrade J, Cortez LD, Campos O, Arruda AL, Pinheiro J, Vulcanis L, Shiratsuchi TS, Kalil-Filho R, Cerri GG. Left ventricular twist: comparison between two- and three-dimensional speckle-tracking echocardiography in healthy volunteers. Eur $\mathbf{J}$ Echocardiogr. 2011; 12(1):76-9. 
46. Lilli A, Baratto MT, Del Meglio J, Chioccioli M, Magnacca M, Talini E, Canale ML, Poddighe R, Comella A, Casolo G. Left ventricular rotation and twist assessed by four-dimensional speckle tracking echocardiography in healthy subjects and pathological remodeling: a single center experience. Echocardiography. 2013; 30(2):171-9.

47. Helle-Valle T, Crosby J, Edvardsen T, Lyseggen E, Amundsen BH, Smith HJ, Rosen BD, Lima JA, Torp H, Ihlen H, Smiseth OA. New noninvasive method for assessment of left ventricular rotation: speckle tracking echocardiography. Circulation. 2005; 112(20):3149-56.

48. Nesser HJ, Mor-Avi V, Gorissen W, Weinert L, Steringer-Mascherbauer R, Niel J, Sugeng L, Lang RM. Quantification of left ventricular volumes using threedimensional echocardiographic speckle tracking: comparison with MRI. Eur Heart J. 2009; 30(13):1565-73.

49. Zhou Z, Ashraf M, Hu D, Dai X, Xu Y, Kenny B, Cameron B, Nguyen T, Xiong L, Sahn DJ. Three-dimensional speckle-tracking imaging for left ventricular rotation measurement: an in vitro validation study. J Ultrasound Med. 2010; 29(6):903-9.

50. van Dalen BM, Caliskan K, Soliman OI, Kauer F, van der Zwaan HB, Vletter WB, van Vark LC, Ten Cate FJ, Geleijnse ML. Diagnostic value of rigid body rotation in noncompaction cardiomyopathy. J Am Soc Echocardiogr. 2011; 24(5):548-55.

51. Soliman OI, Geleijnse ML, Caliskan K, Vletter WB, Ten Cate FJ. Diagnostic uncertainties and future perspectives in noncompaction cardiomyopathy. Expert Opin Med Diagn. 2012; 6(3):221-33.

52. Lofiego C, Biagini E, Ferlito M, Pasquale F, Rocchi G, Perugini E, Leone O, Bracchetti G, Caliskan K, Branzi A, ten Cate FJ, Rapezzi C. Paradoxical contributions of non-compacted and compacted segments to global left ventricular dysfunction in isolated left ventricular noncompaction. Am J Cardiol. 2006; 97(5):738-41

53. Koh C, Hong WJ, Wong SJ, Cheung YF. Systolic-diastolic coupling of myocardial deformation of the left ventricle in children with left ventricular noncompaction. Heart Vessels. 2010; 25(6):493-9.

54. Bellavia D, Michelena HI, Martinez M, Pellikka PA, Bruce CJ, Connolly HM, Villarraga HR, Veress G, Oh JK, Miller FA. Speckle myocardial imaging modalities for early detection of myocardial impairment in isolated left ventricular non-compaction. Heart. 2010; 96(6):440-7. 
55. Kleijn SA, Aly MF, Terwee CB, van Rossum AC, Kamp O. Comparison between direct volumetric and speckle tracking methodologies for left ventricular and left atrial chamber quantification by three-dimensional echocardiography. Am J Cardiol. 2011; 108(7):1038-44.

56. Nemes A, Hausinger P, Kalapos A, Domsik P, Forster T. Alternative ways to assess left atrial function in noncompaction cardiomyopathy by three-dimensional speckle-tracking echocardiography: (a case from the MAGYAR-Path study). Int $\mathbf{J}$ Cardiol. 2012;158(1):105-7.

57. Nemes A, Kalapos A, Domsik P, Forster T. Identification of left ventricular "rigid body rotation" by three-dimensional speckle-tracking echocardiography in a patient with noncompaction of the left ventricle: a case from the MAGYAR-Path Study. Echocardiography. 2012; 29(9):E237-40.

58. Nemes A, Kalapos A, Domsik P, Forster T. [Three-dimensional speckle-tracking echocardiography -- a further step in non-invasive three-dimensional cardiac imaging]. Orv Hetil. 2012; 153(40):1570-7.

59. Yingchoncharoen T, Agarwal S, Popović ZB, Marwick TH. Normal ranges of left ventricular strain: a meta-analysis. J Am Soc Echocardiogr. 2013; 26(2):185-91.

60. Kleijn SA, Brouwer WP, Aly MF, Rüssel IK, de Roest GJ, Beek AM, van Rossum AC, Kamp O. Comparison between three-dimensional speckle-tracking echocardiography and cardiac magnetic resonance imaging for quantification of left ventricular volumes and function. Eur Heart J Cardiovasc Imaging. 2012; 13(10):834-9.

61. Kleijn SA, Aly MF, Terwee CB, van Rossum AC, Kamp O. Reliability of left ventricular volumes and function measurements using three-dimensional speckle tracking echocardiography. Eur Heart J Cardiovasc Imaging. 2012; 13(2):159-68.

62. Saito K, Okura H, Watanabe N, Hayashida A, Obase K, Imai K, Maehama T, Kawamoto T, Neishi Y, Yoshida K. Comprehensive evaluation of left ventricular strain using speckle tracking echocardiography in normal adults: comparison of three-dimensional and two-dimensional approaches. J Am Soc Echocardiogr. 2009; 22(9):1025-30.

63. Duan F, Xie M, Wang X, Li Y, He L, Jiang L, Fu Q. Preliminary clinical study of left ventricular myocardial strain in patients with non-ischemic dilated cardiomyopathy by three-dimensional speckle tracking imaging. Cardiovasc Ultrasound. 2012;10:8. 
64. Kleijn SA, Aly MF, Terwee CB, van Rossum AC, Kamp O. Three-dimensional speckle tracking echocardiography for automatic assessment of global and regional left ventricular function based on area strain. J Am Soc Echocardiogr. 2011; 24(3):314-21.

65. Nemes A, Kalapos A, Domsik P, Forster T. [Left ventricular rotation and twist of the heart. Clarification of some concepts]. Orv Hetil. 2012;153(39):1547-51.

66. van Dalen BM, Caliskan K, Soliman OI, Nemes A, Vletter WB, Ten Cate FJ, Geleijnse ML. Left ventricular solid body rotation in non-compaction cardiomyopathy: a potential new objective and quantitative functional diagnostic criterion? Eur J Heart Fail. 2008; 10(11):1088-93.

67. Serri K, Reant P, Lafitte M, Berhouet M, Le Bouffos V, Roudaut R, Lafitte S. Global and regional myocardial function quantification by two-dimensional strain: application in hypertrophic cardiomyopathy. J Am Coll Cardiol. 20061; 47(6):1175-81.

68. Carasso S, Yang H, Woo A, Vannan MA, Jamorski M, Wigle ED, Rakowski H. Systolic myocardial mechanics in hypertrophic cardiomyopathy: novel concepts and implications for clinical status. J Am Soc Echocardiogr. 2008; 21(6):675-83.

69. Reddy M, Thatai D, Bernal J, Pradhan J, Afonso L. Apical hypertrophic cardiomyopathy: potential utility of Strain imaging. Eur J Echocardiogr. 2008; 9(4):560-2.

70. Jasaityte R, Heyde B, D'hooge J. Current state of three-dimensional myocardial strain estimation using echocardiography. J Am Soc Echocardiogr. 2013; 26(1):15-28.

71. Biswas M, Sudhakar S, Nanda NC, Buckberg G, Pradhan M, Roomi AU, Gorissen W, Houle H. Two- and three-dimensional speckle tracking echocardiography: clinical applications and future directions. Echocardiography. 2013; 30(1):88-105.

72. Urbano-Moral JA, Patel AR, Maron MS, Arias-Godinez JA, Pandian NG. Threedimensional speckle-tracking echocardiography: methodological aspects and clinical potential. Echocardiography. 2012; 29(8):997-1010. 


\section{Acknowledgements}

The studies reported in this work were performed at the 2nd Department of Medicine and Cardiology Center, Medical Faculty, Albert Szent-Györgyi Clinical Center, University of Szeged, Hungary.

I am especially grateful to my supervisor, Prof. Dr. Attila Nemes for the professional advice, valuable ideas, and personal support, which helped my scientific work.

I thank Prof. Dr. Tamás Forster for giving me the opportunity to work in the 2nd Department of Medicine and Cardiology Center, University of Szeged.

I would like to thank Dr. Péter Domsik for his technical assistance, professional advice and support.

Here I would like to say thank you to all the great co-authors, Dr. Csaba Lengyel, Dr. Róbert Sepp, Dr. Andrea Orosz, Dr. Henriette Gavallér.

I thank all my colleagues in the 2nd Department of Medicine and Cardiology Center who supported my work and helped me during these years.

I am grateful to my family and also to my friends for encouraging me and providing safe background for me with their love and patience. 
Photocopies of relevant publications 
I. 
III. 
IV. 
